Key Words:

\#Hybrid Sulfur\#

\#Electrolyzer\#

Retention:

\#Permanent\#

\title{
Final Report on GDE Gap Cell
}

Prepared by

Simon G. Stone of

Giner Electrochemical Systems, LLC

For

Savannah River National Laboratory

\author{
W.A. Summers \\ E.T. Danko \\ D.T. Herman
}

September, 2009

Savannah River National Laboratory

Savannah River Nuclear Solutions

Aiken, SC 29808

Prepared for the U.S. Department of Energy Under

Contract Number DE-AC09-08SR22470

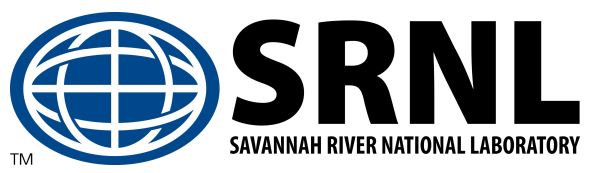




\section{DISCLAIMER}

THIS WORK WAS PREPARED UNDER AN AGREEMENT WITH AND FUNDED BY THE U.S. GOVERNMENT. NEITHER THE U. S. GOVERNMENT OR ITS EMPLOYEES, NOR ANY OF ITS CONTRACTORS, SUBCONTRACTORS OR THEIR EMPLOYEES, MAKES ANY EXPRESS OR IMPLIED:

1. WARRANTY OR ASSUMES ANY LEGAL LIABILITY FOR THE ACCURACY, COMPLETENESS, OR FOR THE USE OR RESULTS OF SUCH USE OF ANY

INFORMATION, PRODUCT, OR PROCESS DISCLOSED; OR

2. REPRESENTATION THAT SUCH USE OR RESULTS OF SUCH USE WOULD NOT INFRINGE PRIVATELY OWNED RIGHTS; OR

3. ENDORSEMENT OR RECOMMENDATION OF ANY SPECIFICALLY IDENTIFIED COMMERCIAL PRODUCT, PROCESS, OR SERVICE.

ANY VIEWS AND OPINIONS OF AUTHORS EXPRESSED IN THIS WORK DO NOT NECESSARILY STATE OR REFLECT THOSE OF THE UNITED STATES

GOVERNMENT, OR ITS CONTRACTORS, OR SUBCONTRACTORS.

PRINTED IN THE UNITED STATES OF AMERICA

PREPARED FOR

U.S. DEPARTMENT OF ENERGY 
Key Words:

\#Hybrid Sulfur\#

\#Electrolyzer\#

Retention:

\#Permanent\#

\title{
Final Report on GDE Gap Cell
}

Prepared by

Simon G. Stone of

Giner Electrochemical Systems, LLC

For

Savannah River National Laboratory

\author{
W.A. Summers \\ E.T. Danko \\ D.T. Herman
}

September, 2009 
Attached is the final report on the Evaluation of the Narrow Gap Anode Cell for the Hybrid Sulfur Process. This report satisfies Milestone NSR07TC030112 of Work Package \#:

NSR07TC0301, Hybrid Sulfur Electrolyzer Development. 
Final Report on GDE Gap Cell

Simon G. Stone

Giner Electrochemical Systems, LLC

Prepared

September, 2009

For

Savannah River National Laboratory 


\section{SRNL-OS-2009-00070, REVISION 0}

\section{LIST OF FIGURES}

Figure 1. Test system schematic for $25-\mathrm{cm}^{2}$ NGA-HyS cell.................................................

Figure 2. Photograph of test stand used for initial HyS electrolyzer evaluation studies................

Figure 3. Photograph of assembled NGA-HyS electrolyzer cell (with PEEK fittings). ................

Figure 4. Exploded view of $25-\mathrm{cm}^{2}$ narrow gap electrolysis cell..............................................xi

Figure 5. Photos of the Cell Components......................................................................... xii

Figure 6. Summary of HyS configurations tested. ............................................................... xii

Figure 7. Polarization scans for various builds in hydrogen pump mode at $80^{\circ} \mathrm{C}$.................. xiii

Figure 8. HyS polarization Scans for Build USC-02. ..............................................................

Figure 9. Anolyte acidity and catholyte water out-flow vs. current density for the USC-type

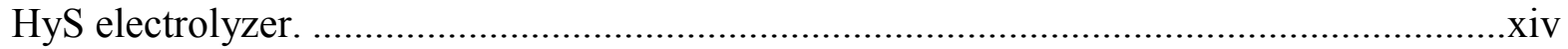

Figure 10. HyS polarization scan for Build NGA-01 compared to previous work.......................

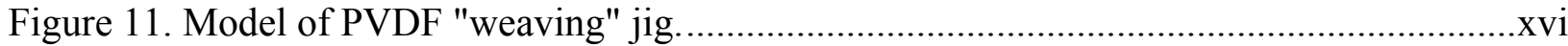

Figure 12. Plan and edge (insert) view of PVDF anolyte gap support.......................................

Figure 13. HyS polarization scan for NGA-02/03 .......................................................... xvii

Figure 14. HyS polarization scans for Build NGA-04 ...................................................... xviii

Figure 15. HyS polarization scans for Build NGA-05 ........................................................

Figure 16. Membrane from Build NGA-05 showing cathode-side sulfur deposits.....................xix

Figure 17. HyS polarization scans for Build NGA-06. .....................................................x

Figure 18. Timeplot of NGA-07 operating at $500 \mathrm{~mA} / \mathrm{cm}^{2}$ with $1.3 \mathrm{x} \mathrm{SO}_{2}$ stoichiometry...........xxi

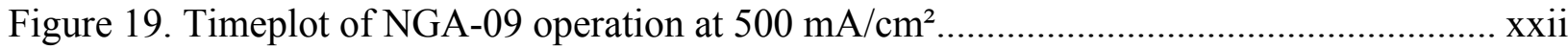

Figure 20. Polarization performance of NGA-10, which utilized a flocced/vacuum cast anode

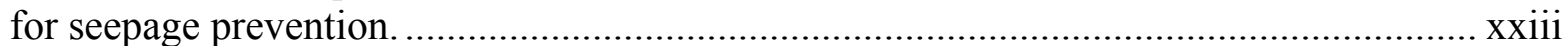

Figure 21. Hydrogen pump testing of NGA-11 and NGA-12 builds, as compared to "open

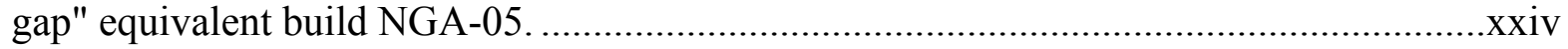

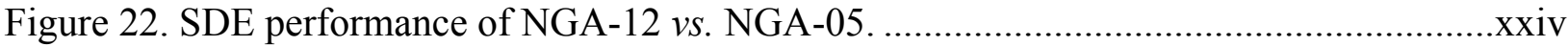

Figure 23. Photograph from the anode side of the MEA from NGA-12 after disassembly, showing regions of differential sulfur layer formation on the cathode..............................x

Figure 24. Model (section) view of proposed chamfering of serpentine flowfield to maximize electrolyte access; the flowfield used in testing is shown to the left. ................................xv

Figure 25. Calculated acid concentration in anolyte produced at $500 \mathrm{~mA} / \mathrm{cm}^{2}$ in the NGA electrolyzer at different water transport rates and $30 \% \mathrm{H}_{2} \mathrm{SO}_{4}$ anolyte in flowrates...........xxvi

Figure 26. Comparison of observed performance between NGA-13 (blue line) and direct-feed

(USC-type, red line) electrolyzer at $80^{\circ} \mathrm{C}$; both MEAs use Nafion 1135 membrane....... xxvii

Figure 27. Comparison of projected $\mathrm{iR}$ voltage loss in the NGA electrolyzer at varying concentration of anolyte, gap thickness, and PEM thickness. The nominal NGA-13 operating configuration is denoted by the black circles (1/32" gap, N1135 membrane, $40 \% \mathrm{H}_{2} \mathrm{SO}_{4}$ ). xxviii

Figure 28. Photograph of SDE test stand modified for endurance testing. ..............................xix

Figure 29. Timeplot of NGA-13 endurance testing over 13.7 hour run.................................xxx

Figure 30. Graph of polarization scans during $80^{\circ} \mathrm{C}$ endurance testing of the NGA-13 build. .xxx Figure 31. Chart of endurance test dates and durations (left) and graph of voltages observed

for NGA-13 during endurance testing at $80^{\circ} \mathrm{C}$ and 1.02-1.05x $\mathrm{SO}_{2}$ stoichiometry (right).xxxi

Figure 32. Graph of observed anolyte conductivity (temperature-compensated to $20^{\circ} \mathrm{C}$ ) and cell voltage $v s$. titrated anolyte acid strength for NGA-13 endurance testing. ................. xxxii

Figure 33. Plot showing trend of observed $\mathrm{SO}_{2}$ crossover vs. average current density.......... xxxii 
Figure 34. Plot showing trend of observed $\mathrm{SO} 2$ crossover vs. anode $\mathrm{SO}_{2}$ stoichiometry....... xxxii

Figure 35. Photograph of uncatalyzed membrane in test hardware during initial stages of sulfur formation.

Figure 36. Photograph of uncatalyzed membrane out of test hardware showing distinct areas of sulfur formation. .xxxiv 
TABLE OF CONTENTS

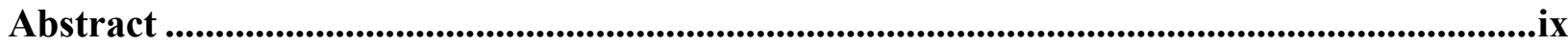

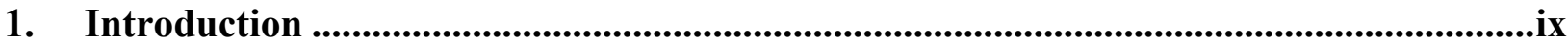

2. Results and Discussion ..................................................................................................................

2.1. Design and Fabrication of Low Pressure $\mathrm{SO}_{2}$ Test Stand ...........................................ix

2.2. Baseline HyS Testing.......................................................................................................... xii

2.3. Sulfur dioxide crossover measurements ..................................................................... xiii

2.4. USC-Type HyS Tests ................................................................................................................

2.5. NGA-HyS Testing ..................................................................................................

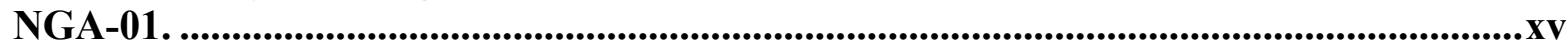

NGA-02/03. ......................................................................................................................

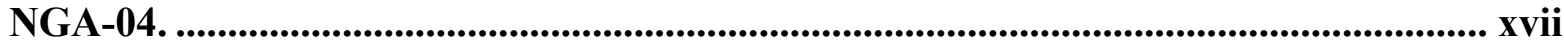

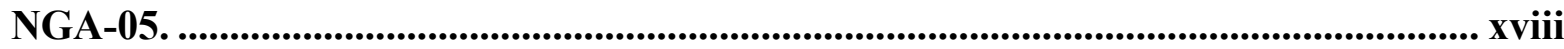

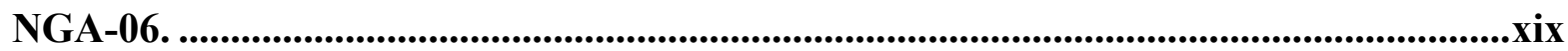

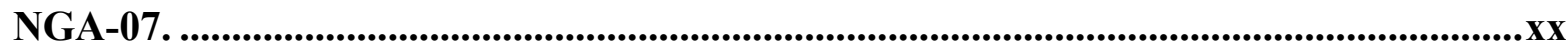

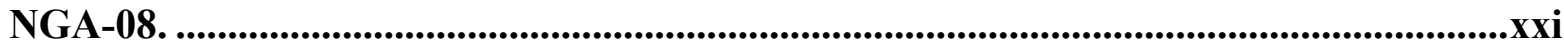

NGA-09.

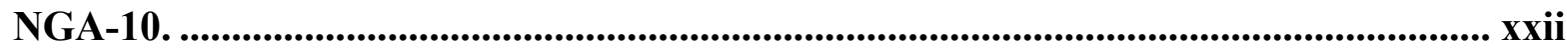

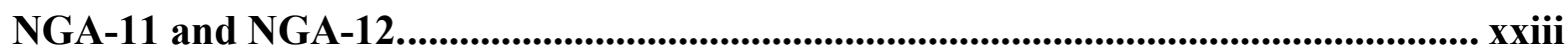

2.6. Sulfur crossover ........................................................................................................ xxxii

2.7. NGA-HyS Design Study System and Cost Projections ............................................xxxiv 


\begin{abstract}
A project has been undertaken to develop an electrochemical cell and support equipment for evaluation of a gas diffusion electrode-based, narrow-electrolyte-gap anode for $\mathrm{SO}_{2}$ oxidation in the hydrogen production cycle of the hybrid sulfur (HyS) process. The project supported the HyS development program at the Savannah River National Lab (SRNL). The benefits of using a gas diffusion electrode in conjunction with the narrow anolyte gap are being determined through electrochemical polarization testing under a variety conditions, and by comparison to results produced by SRNL and others using anode technologies that have no anolyte gap. These test results indicate that the NGA cell has low resistance suitable for use in the HyS electrolyzer, exhibits good efficiency at high current densities compared to the direct feed HyS electrolyzer, and indicates robust performance in extended testing over 65 hours. Seepage episodes were mostly caused by port clogging, which can be mitigated in future designs through minor modifications to the hardware. Significant reductions in sulfur crossover have not yet been demonstrated in the NGA configuration compared to in-house direct feed testing, but corroborative sulfur layer analysis is as yet incomplete. Further testing in a single-pass anolyte configuration is recommended for complete evaluation of steady-state electrochemical efficiency and $\mathrm{SO}_{2}$ crossover in the narrow gap configuration.
\end{abstract}

\title{
INTRODUCTION
}

The use of a sulfur dioxide depolarized gas diffusion electrode within the hybrid sulfur process is being investigated, and a sulfur dioxide gas depolarized anode in sulfuric acid has been demonstrated in an unseparated cell at Giner Electrochemical Systems (GES). The use of a gas-diffusion electrode (GDE) in a narrow-gap electrolyzer (NGA) opens new avenues of cell design and potentially provides a means of addressing sulfur dioxide crossover, proton-exchange membrane (PEM) water supply, cell pressure control, and anode mass transfer limitations. This effort is demonstrating a $25-\mathrm{cm}^{2}$ bench scale PEM electrolyzer.

The HyS electrolyzer originally developed by Westinghouse employs an $\mathrm{SO}_{2}$-saturated sulfuric acid solution as the anode-feed. To sustain high current densities and cell efficiency, high $\mathrm{SO}_{2}$ concentrations are necessary, which requires pressurization of the anolyte stream to 4-20 bar. The NGA-HyS electrolyzer is intended to operate using a feed of pure $\mathrm{SO}_{2}$ gas to the anode and at relatively low pressures. This "direct feed" style is similar to the HyS electrolyzer configuration developed at the University of South Carolina ("USC-type" configuration) in the laboratory of Prof. John Weidner. The NGA-HyS approach is unique in that it incorporates an electrolyte gap between the anode GDE and the electrolyzer PEM separator, the hypothesis being that the gap will allow better control of anolyte composition and will shield the PEM from exposure to $\mathrm{SO}_{2}$ gas and high concentrations of dissolved $\mathrm{SO}_{2}$. The diffusion of $\mathrm{SO}_{2}$ to the cathode side of the PEM separator results in a loss of anode "fuel" and causes the formation of elemental sulfur deposits under certain conditions. The NGA-HyS development work detailed herein addresses the following questions:

- Can the HyS electrolyzer perform nominally with the addition of an electrolyte gap?

- Does the gap minimize $\mathrm{SO}_{2}$ loss to the HyS electrolyzer cathode?

- Does the NGA-HyS configuration lend itself to large-scale electrolysis?

\section{RESULTS AND DISCUSSION}

\section{DESIGN AND FABRICATION OF LOW PRESSURE $\mathrm{SO}_{2}$ TEST STAND}

To support flow and temperature control and monitoring of the NGA-HyS electrolyzer, a test stand was designed and constructed. An existing test stand was modified for this purpose by the addition of a peristaltic tubing pump, a high current power supply (12.5V/60A, Lambda Americas, Neptune, NJ), manifolding for diagnostic gasses (nitrogen, hydrogen), and vessels for gas-liquid separation and sulfur gas scrubbing from the hydrogen product. The design of the test stand used in these studies is diagrammed in Figure 1 and shown in Figure 2. While the test system was plumbed for cathode water flush, it was observed early on in the testing that providing water to the cathode had no effect on cell voltage, so the results provided herein were obtained without any cathode water flush. 


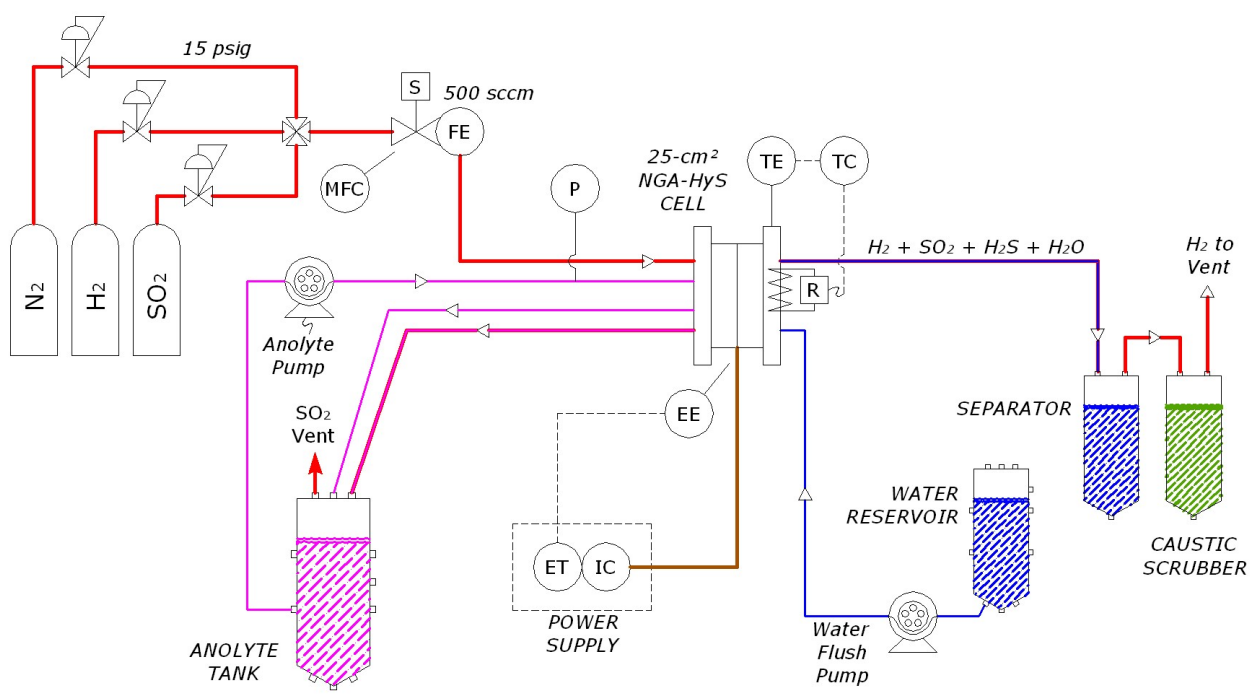

Figure 1. Test system schematic for $25-\mathrm{cm}^{2}$ NGA-HyS cell.

Existing $25-\mathrm{cm}^{2}$ cell hardware was employed as much as possible in the construction of the test cell. Some modifications to materials of construction were required to ensure safe and contamination-free electrolyzer operation. The cell collectors required the use of an inert, non-porous graphite material; per SRNL suggestion, we employed material supplied by Electrochem, Inc. (Woburn, MA). Various fittings were also replaced with those of appropriate materials of construction. Hastelloy B-2 alloy was used initially for these fittings but, as corrosion was an immediately apparent issue, poly(etheretherketone) (PEEK) plastic fittings were thereafter fabricated and used without any problems. (It should be noted that the PEEK material is useful only up to about 70 -wt \% hot sulfuric acid, at which point the polymer backbone becomes sulfonated and soluble). Fluorinated ethylene propylene (FEP) plastic was used for tubing runs and for the anolyte gap frame, while commercially pure tantalum $(99.85 \%)$ woven wire mesh was used in the gap support $(30$ x 30 wires/inch, 0.0030 " wire diameter, $83 \%$ open area; Unique Wire Weaving Co., Hillside, NJ). The assembled $25-\mathrm{cm}^{2}$ NGA-HyS hardware is shown in Figure 3, an exploded model view of the cell is shown in Figure 4, and photos of the individual cell

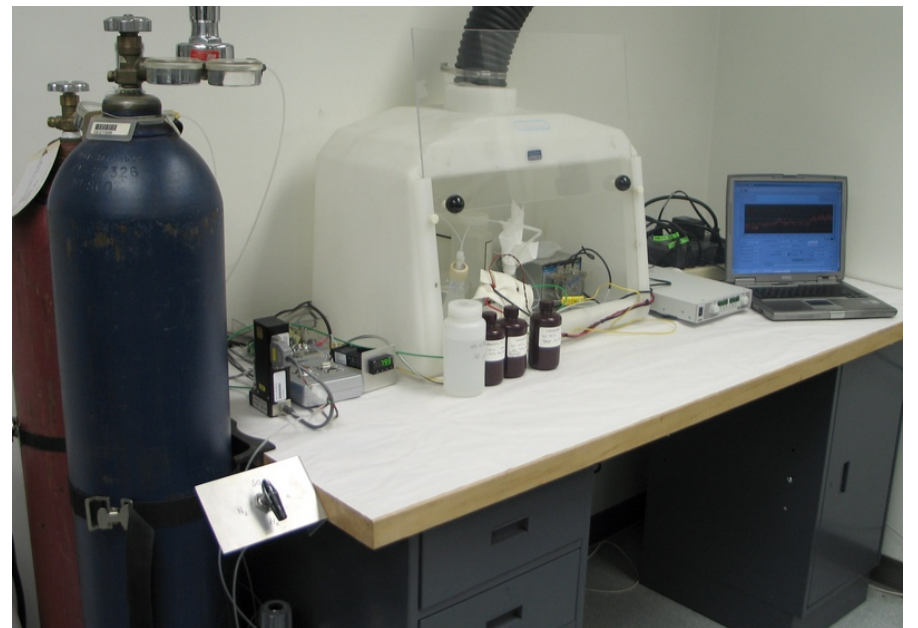

FIGURE 2. PHOTOGRAPH OF TEST STAND USED FOR INITIAL HYS ELECTROLYZER EVALUATION STUDIES.

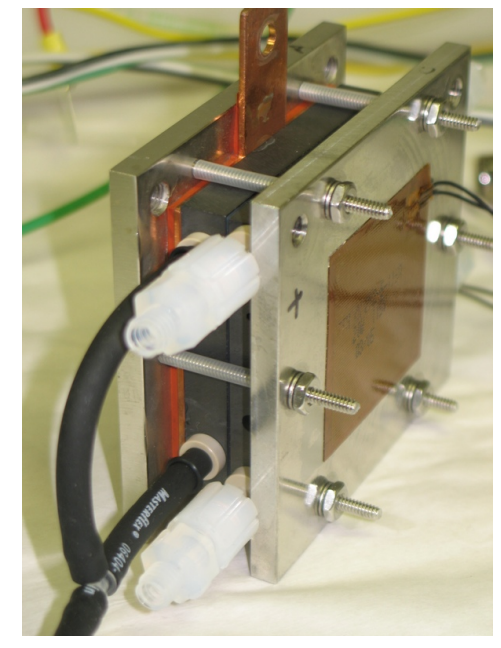

FIGURE 3. PHOTOGRAPH OF ASSEMBLED NGA-HYS ELECTROLYZER CELL (WITH PEEK FITTINGS).

components are shown in Figure 5. 


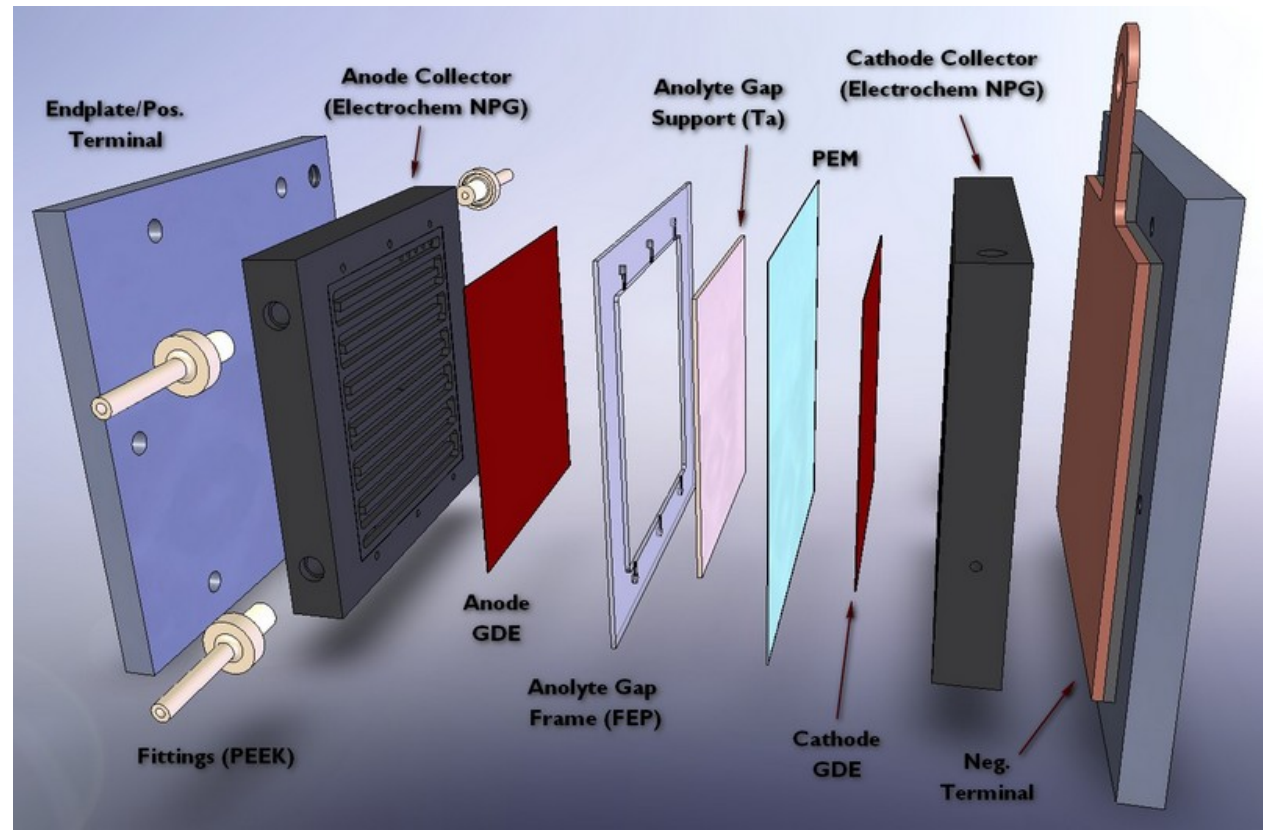

Figure 4. Exploded view of $25-\mathrm{cm}^{2}$ narrow gap electrolysis cell.

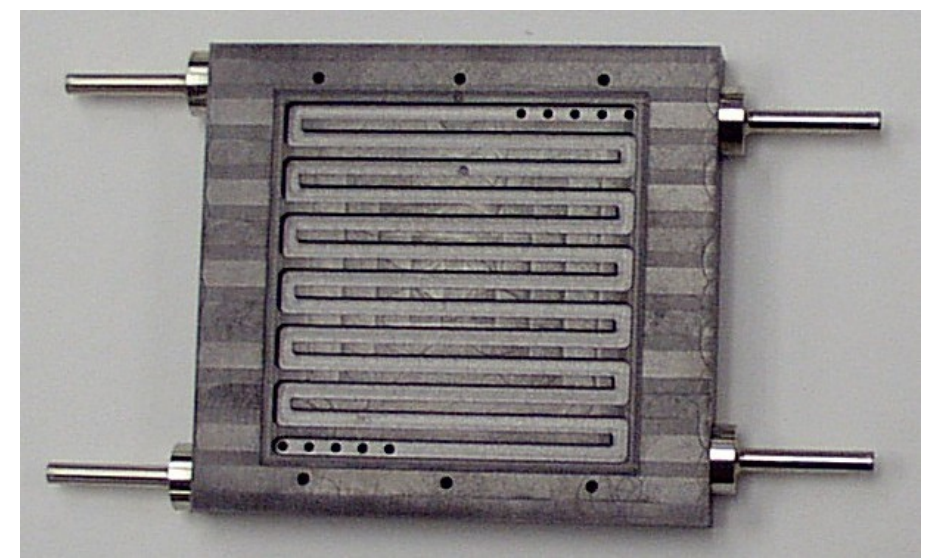

ANODE COLLECTOR (WITH ORIGINAL HASTELLOY B-2 FITTINGS)

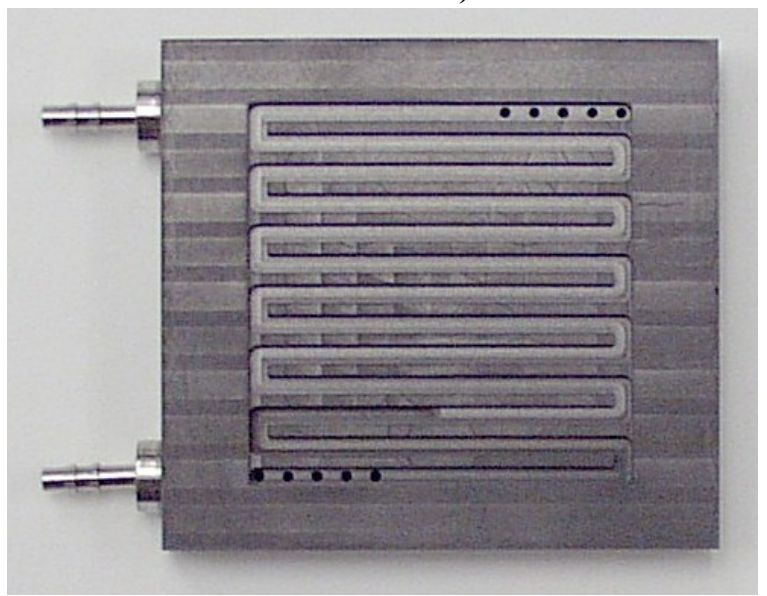

CATHODE COLLECTOR

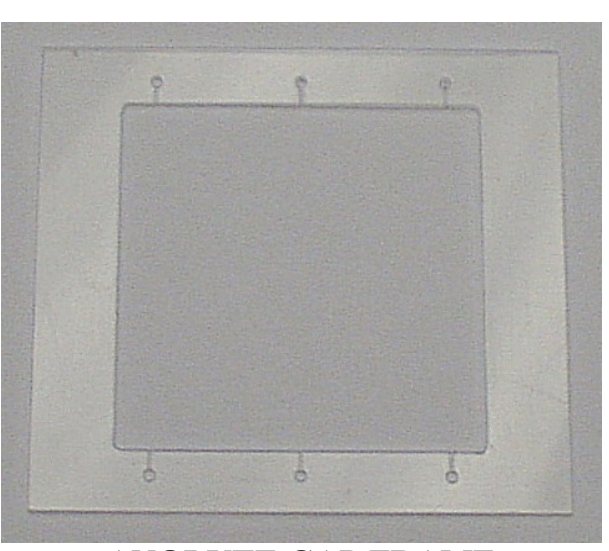

ANOLYTE GAP FRAME

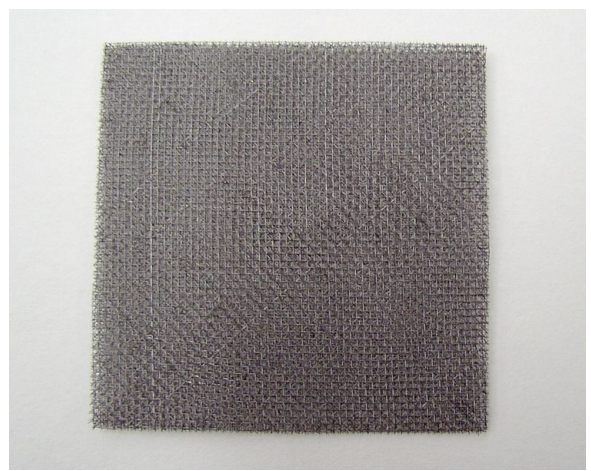

ANOLYTE GAP SUPPORT 
SRNL-OS-2009-00070, REVISION 0

Figure 5. Photos of the Cell Components

\section{BASELINE HYS TESTING}

The first stage of this project was to design and procure/fabricate the cell current collector/flow field plates and the gap frame and support materials needed for the NGA-HyS cell. As these tasks took some time due to machining lead times, the test stand was put into working order and some initial testing was done to establish comparative baseline performance in the USC-type HyS electrolysis mode, using our standard $25-\mathrm{cm}^{2}$ cell hardware. Subsequent tests in the NGA configuration were compared to these baseline USC-type tests; Figure 6 shows a summary of the USC-type and NGA configurations tested under this program.

\begin{tabular}{|c|c|c|c|c|c|c|c|c|c|c|c|c|c|c|c|c|c|c|c|}
\hline 을 & $\begin{array}{l}\text { 山े } \\
0 \\
0 \\
\frac{0}{0} \\
\frac{0}{4}\end{array}$ & 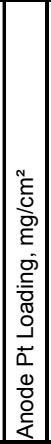 & 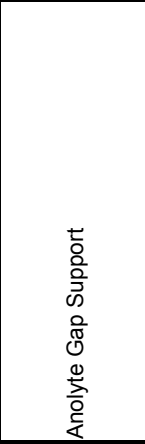 & 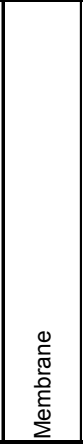 & 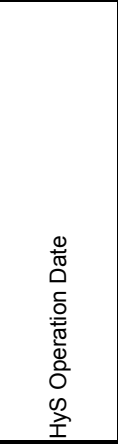 & $\begin{array}{l}\infty \\
\mathbb{1} \\
\mathbb{1} \\
\mathbb{\pi} \\
\infty \\
\stackrel{\infty}{E}\end{array}$ & 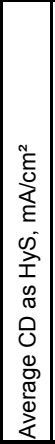 & 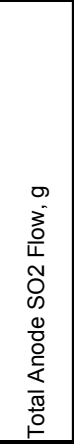 & 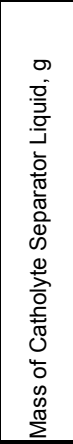 & 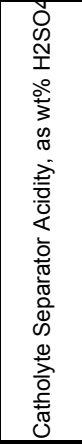 & 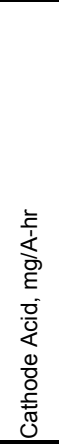 & 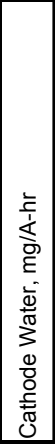 & 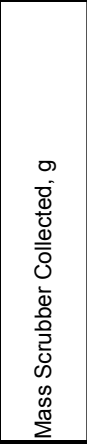 & 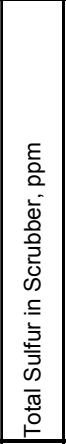 & 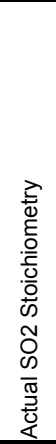 & 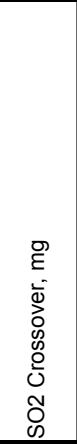 & 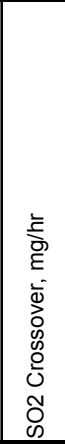 & 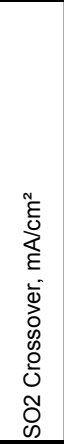 & 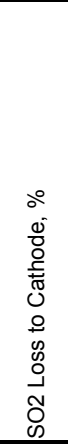 \\
\hline \multirow{2}{*}{ USC-01 } & \multirow{2}{*}{ Std. } & \multirow{2}{*}{0.6} & -- & N115 & 7-Feb-08 & 4.48 & 291 & 60.55 & & & & & 47.04 & 1145 & 1.56 & 107.7 & 24.0 & 0.81 & $0.18 \%$ \\
\hline & & & - & N115 & 11-Feb-08 & 6.40 & 485 & 95.69 & & & & & 80.61 & 751 & 1.03 & 121.1 & 18.9 & 0.63 & $0.13 \%$ \\
\hline USC-02 & Std. & 0.6 & -- & N115 & 4-Mar-08 & 4.79 & 473 & \begin{tabular}{|l|}
69.41 \\
\end{tabular} & & & & & 54.74 & 2115 & 1.03 & 231.6 & 48.3 & 1.62 & $0.33 \%$ \\
\hline NGA-01 & Std. & 0.6 & \begin{tabular}{|l|} 
Ta Screen \\
\end{tabular} & N115 & 13-Mar-08 & 0.70 & 189 & 6.01 & & & & & \multicolumn{7}{|c|}{ No Scrubber Collected } \\
\hline NGA-02/03 & Std. & 0.6 & PVDF Screen & $\mathrm{N} 115$ & 10-Jun-08 & 5.64 & 45 & 31.26 & 4.00 & $0.07 \%$ & 0.26 & 393 & 51.67 & 1973 & 4.12 & 203.9 & 36.2 & 1.21 & $0.65 \%$ \\
\hline NGA-04 & "All PTFE" & 0.6 & Ta Screen & $\mathrm{N} 117$ & 22-Jun-08 & 2.69 & 26 & 19.76 & & & & & 147.05 & 445 & 9.47 & 130.9 & 48.7 & 1.63 & $0.66 \%$ \\
\hline NGA-05 & "All PTFE" & 0.6 & Ta Screen & N1135 & 22-Jul-08 & 4.07 & 22 & 63.81 & & & & & 139.83 & 1582 & 23.9 & 442.4 & 108.7 & 3.64 & $0.69 \%$ \\
\hline NGA-06 & $\begin{array}{l}\text { "Nafion/C } \\
\text { Prelayer" }\end{array}$ & 0.9 & Ta Screen & N117 & 30-Jul-08 & 1.02 & 372 & 12.72 & 0.68 & & & 45 & 41.46 & 122 & 1.12 & 10.1 & 9.9 & 0.33 & $0.08 \%$ \\
\hline NGA-07 & "ETEK" & 4.0 & Ta Screen & N1135 & 7-Aug-08 & 5.30 & 499 & 79.13 & 3.30 & & & 31 & 51.04 & 6393 & 1 & 652.6 & 123.1 & 4.13 & $0.82 \%$ \\
\hline NGA-08 & "All PTFE" & 0.6 & Ta Screen & N1135 & 18-Aug-08 & 3.52 & 482 & 60.72 & 3.26 & & & 48 & 29.15 & 3726 & 1.2 & 217.2 & 61.7 & 2.07 & $0.36 \%$ \\
\hline NGA-09 & "All PTFE" & 0.6 & Ta Screen & N117 & 26-Aug-08 & 2.29 & 356 & 37.35 & & & & & 24.79 & 471 & 1.53 & 23.4 & 10.2 & 0.34 & $0.06 \%$ \\
\hline USC-03 & Std. & 0.6 & -- & N115 & 4-Sep-08 & 5.04 & 210 & 50.3 & & & & & 299.35 & 401 & 1.59 & 240.1 & 47.6 & 1.60 & $0.48 \%$ \\
\hline \multirow{2}{*}{ NGA-10 } & \multirow{2}{*}{ Flocced/VC } & \multirow{2}{*}{1.0} & \multirow{2}{*}{ Ta Screen } & \multirow{2}{*}{ N1135 } & 25-Sep-08 & 4.94 & 456 & \begin{tabular}{|l|}
71.32 \\
\end{tabular} & 22.59 & $0.16 \%$ & 0.40 & 250 & 171.43 & 2505 & 1.06 & 858.9 & 173.9 & 5.82 & $1.20 \%$ \\
\hline & & & & & 30-Sep-08 & & & & 10.54 & $4.23 \%$ & & & \begin{tabular}{|l|}
65.11 \\
\end{tabular} & 1787 & & 232.7 & & & \\
\hline NGA-11 & "All PTFE" & 0.6 & $.063 "$ Serp & N1135 & \multicolumn{15}{|c|}{ No Scrubber Collected } \\
\hline NGA-12 & "All PTFE" & 0.6 & $.032 "$ Serp & N1135 & 22-Oct-08 & 4.59 & 296 & 47.3 & 2.82 & $0.16 \%$ & 0.08 & 52 & 135.5 & 540 & 1.17 & 146.3 & 31.9 & 1.07 & $0.31 \%$ \\
\hline \multirow{10}{*}{ NGA-13 } & \multirow{10}{*}{ "ETEK" } & \multirow{10}{*}{4.0} & \multirow{10}{*}{ Ta Screen } & \multirow{10}{*}{ N1135 } & 11-Nov-08 & 5.77 & 478 & 87.55 & 12.91 & $2.58 \%$ & 3.02 & 114 & 181.32 & 1455 & 1.06 & 527.6 & 91.4 & 3.06 & $0.60 \%$ \\
\hline & & & & & 14-Nov-08 & 5.57 & 492 & 87.33 & 4.67 & $0.08 \%$ & 0.03 & 43 & 396.41 & 1328 & 1.07 & 1052.9 & 189.0 & 6.33 & $1.21 \%$ \\
\hline & & & & & 18-Nov-08 & 7.89 & 486 & 120.2 & 6.22 & $0.08 \%$ & 0.03 & 41 & 306.1 & 976 & 1.05 & 597.5 & 75.7 & 2.54 & $0.50 \%$ \\
\hline & & & & & 19-Nov-08 & 13.70 & 493 & 211.7 & 16.34 & $0.16 \%$ & 0.10 & 60 & 359.95 & 1977 & 1.05 & 1423.2 & 103.9 & 3.48 & $0.67 \%$ \\
\hline & & & & & 20-Nov-08 & 7.17 & 495 & 111.3 & 8.53 & $0.16 \%$ & 0.10 & 60 & 366.01 & 831 & 1.05 & 608.3 & 84.8 & 2.84 & $0.55 \%$ \\
\hline & & & & & 21-Nov-08 & 8.34 & 488 & 127.6 & 9.11 & $0.16 \%$ & 0.09 & 56 & 379.82 & 1405 & 1.05 & 1067.3 & 128.0 & 4.29 & $0.84 \%$ \\
\hline & & & & & 25-Nov-08 & 5.41 & 419 & 71.13 & & & & & 247.9 & & 1.05 & & & & \\
\hline & & & & & 5-Dec-08 & 3.20 & 452 & 43.92 & & & & & \multirow{3}{*}{\multicolumn{2}{|c|}{$\begin{array}{c}\text { No Scrubber } \\
\text { Collected }\end{array}$}} & 1.02 & \multirow{3}{*}{\multicolumn{4}{|c|}{ No Scrubber Collected }} \\
\hline & & & & & 8-Dec-08 & 4.68 & 495 & 72.76 & & & & & & & 1.05 & & & & \\
\hline & & & & & 9-Dec-08 & 6.80 & 479 & 112.6 & & & & & & & 1.16 & & & & \\
\hline
\end{tabular}

Figure 6. Summary of HyS configurations tested.

The evaluation of the HyS electrolyzer performance was complimented in this program by routine "hydrogen pump" testing. In hydrogen pump testing the anode is fed with hydrogen gas in place of the $\mathrm{SO}_{2}$. As the anodic hydrogen oxidation (and cathodic hydrogen evolution) kinetics are extremely fast, hydrogen pump polarization plots (cell volts vs. current density) are dominated by the ohmic resistance of the cell. The ohmic resistance is comprised of the serial contributions of the various current-carrying cell parts: collector plates, GDE, catalyst layer, electrolyte, and PEM. Thus, the inclusion of hydrogen pump testing before HyS operation $\left(\mathrm{SO}_{2}\right.$ anode, hydrogen evolving cathode) provides a reliable means of qualifying the mechanical buildup and normalizing the observed HyS performance to the apparent ohmic limitations of the cell under study. The hydrogen pump results are shown in Figure 7 below. For the USC-type tests, the cathode was fed 1-2 g/min of distilled water, while for the NGA testing, the anolyte gap was fed with $1-2 \mathrm{~g} / \mathrm{min}$ of $30 \% \mathrm{H}_{2} \mathrm{SO}_{4}$. The hydrogen stoichiometry was 1.02-1.2x; no sensitivity to stoichiometry was observed for any of the cells above $1.02 \mathrm{x}$. 
SRNL-OS-2009-00070, REVISION 0

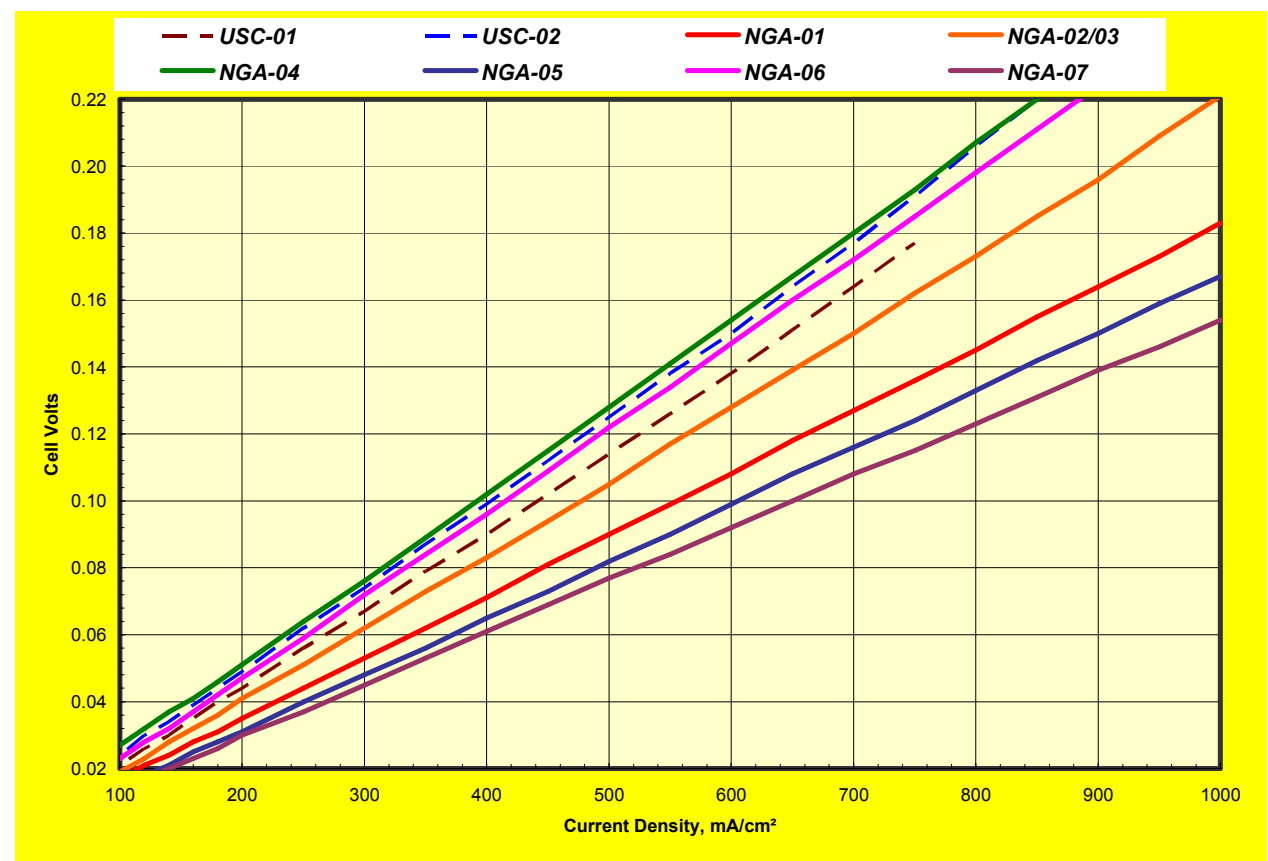

Figure 7. Polarization scans for various builds in hydrogen pump mode at $80^{\circ} \mathrm{C}$.

The standard GDEs used for the anode and cathode in this work were fabricated by GES techniques following the composition described by Weidner's group in their HyS electrolyzer work. ${ }^{1}$ The GDE support was Toray H060 with $0.2 \mathrm{mg} / \mathrm{cm}^{2}$ PTFE wetproofing, which was first coated with a microporous layer $\left(0.6 \mathrm{mg} / \mathrm{cm}^{2} \mathrm{C} / 40\right.$ wt- $\%$ PTFE), then coated with a catalyst layer $\left(0.6 \mathrm{mg} / \mathrm{cm}^{2} \mathrm{Pt}\right.$ (on C) $/ 33 \mathrm{wt}-\%$ Nafion). This standard GDE was used on the cathode for every cell tested to date in this program. A 0.031 " anolyte gap frame was used for all of the NGA-HyS electrolyzer testing. All of the reported results were obtained at $80^{\circ} \mathrm{C}$ using $30-31 \mathrm{wt} \%$ sulfuric acid anolyte, unless otherwise noted.

\section{SULFUR DIOXIDE CROSSOVER MEASUREMENTS}

A significant portion of this program was dedicated to developing means of measuring the amount of $\mathrm{SO}_{2}$ lost to the cathode stream of the HyS electrolyzer. Because the $\mathrm{SO}_{2}$ that reaches the cathode undergoes reaction to form hydrogen sulfide and elemental sulfur, it is important to capture all species in order to quantitate total $\mathrm{SO}_{2}$ crossover. The water which evolves from the hydrogen cathode (catholyte) may contain sulfuric acid (diffusion from the anode side of the PEM) and dissolved or suspended sulfur, in addition to hydrogen sulfide and unreacted $\mathrm{SO}_{2}$. Therefore, a separation of the acidic catholyte from the hydrogen gas allows the quantification of the sulfur species in the gas phase free from interference from sulfuric acid, which is not formed from $\mathrm{SO}_{2}$ on the cathode.

GES first surveyed existing technologies for liquid and gas phase analysis of these two streams, which include gas phase infrared/UV absorption and UV/Vis fluorescence spectroscopy; gas chromatography; ion chromatography; and electrochemical detection. Though all of these methods required too significant an expense to evaluate for the HyS process development in this program, we believe that gas chromatography (with TCD or sulfur detector) and ion chromatography (IC) techniques will serve in the future to greatly benefit the study of the cathode sulfur chemistry. Though some development will probably need to be done in concert with an IC column manufacturer, the capability of IC to identify and quantify the various species in the HyS catholyte is especially promising.

\footnotetext{
${ }^{1}$ Sivasubramanian, P., Ramasamy, R.P, Freire, F.J., Holland, C.E. and Weidner, J. W., "Electrochemical hydrogen production from thermochemical cycles using a proton exchange membrane electrolyzer," International Journal of Hydrogen Energy, 32(4), 463-468 (2007)).
} 
GES also attempted to develop redox titration and gravimetric methods for determination of the sulfide, sulfite and sulfate species possible present in the catholyte. The iodometric titration of sulfite ion-bearing solutions was reasonably successful (within $15 \%$ of known concentration), but the methods developed in general were neither precise enough nor sufficiently selective to provide quantitative speciation of the catholyte.

As speciation of the non-sulfate species is not crucial to determining $\mathrm{SO}_{2}$ crossover, a simple method was devised for this determination: the hydrogen gas evolved from the catholyte separator is passed through a caustic scrubber solution to isolate the $\mathrm{H}_{2} \mathrm{~S}$ and $\mathrm{SO}_{2}$ gasses entrained therein, then this scrubber solution is weighed and sent to out to an analytical lab for total sulfur (as ppm $\mathrm{S}$ ) analysis by oxygen bomb and ion chromatography (ASTM D 129-00(2005)/ASTM D 4327-03). Because the $\mathrm{H}_{2} \mathrm{~S}$ and $\mathrm{SO}_{2}$ in the hydrogen gas are in equilibrium with the liquid separator contents, the gas phase should carry most of these species over long operating times. The low vapor pressure of $\mathrm{H}_{2} \mathrm{SO}_{4}$ ensures that there is no sulfate interference in the scrubbed solution. What will be done in future testing is, after HyS operation is complete, the separator will be flushed thoroughly with nitrogen gas to strip dissolved $\mathrm{SO}_{2}$ and $\mathrm{H}_{2} \mathrm{~S}$ into the scrubber, thus improving the accuracy of this technique. It should be noted that any dissolved elemental sulfur or other non-volatile, nonsulfate species remaining in the catholyte are not quantitated by this technique.

\section{USC-TYPE HYS TESTS}

Typical results for USC-type HyS electrolyzer are reported below. The MEA and hardware configuration were: $25-\mathrm{cm}^{2}$ active area, $0.67 \mathrm{mg} / \mathrm{cm}^{2} \mathrm{Pt} / \mathrm{C}$ anode \& cathode, Nafion 115. A cell (Build USC-02) was operated for a total of just under $5 \mathrm{hrs}$ at current densities between 100 and $900 \mathrm{~mA} / \mathrm{cm}^{2}$, mostly at $500 \mathrm{~mA} / \mathrm{cm}^{2}$. The operating conditions were: $80^{\circ} \mathrm{C}$ cell temp., $1.2 \mathrm{~g} / \mathrm{min}$ DI water flow to cathode, $1.02 \mathrm{x}$ stoich dry sulfur dioxide flow to anode. In the polarization scan given as Figure 8 shows, the polarization behavior changed over the course of testing. Between 10AM and 1PM, the cell was held sequentially at 500,750 , and $250 \mathrm{~mA} / \mathrm{cm}^{2}$ while collecting unique anolyte and catholyte samples over each duration of $\sim 1 \mathrm{hr}$ each. The 1PM polarization line below shows the steady-state voltages obtained under these conditions.

It should be noted that these types of cell polarization variations are typical of all of the HyS electrolyzer builds tested at GES. Some of the possible sources of such hysteresis include membrane dehydration, anode or cathode catalyst poisoning, and catalyst layer flooding. Future studies planned at GES include HyS testing with a reference electrode, which should provide useful insight into sources of electrode polarization, especially poisoning.

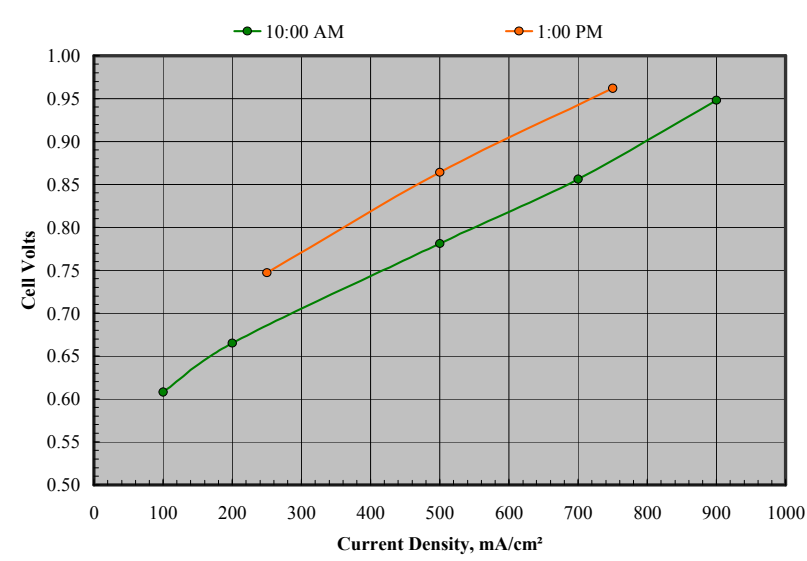

FIGURE 8. HYS POLARIZATION SCANS FOR BUILD USC-02.

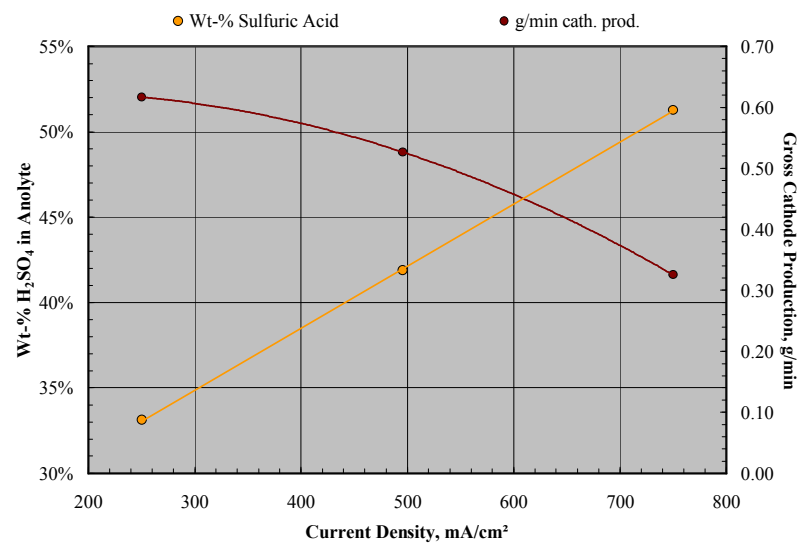

FIGURE 9. ANOLYTE ACIDITY AND CATHOLYTE WATER OUT-FLOW VS. CURRENT DENSITY FOR THE USC-TYPE HYS ELECTROLYZER.

It is also useful to note from the USC-type testing that the water balance in the cell is driven strongly by current density. As shown in Figure 9, the sulfuric acid produced at the anode is much more concentrated at high current densities; the mass flow of water leaving the cathode is also significantly reduced under these 
conditions. These observations are consistent with a water diffusion limitation, wherein the water supplied to the cathode is driven to the anode side of the PEM by a large concentration gradient.

\section{NGA-HYS TESTING}

NGA-01. The 1st narrow-gap anode HyS cell was NGA-01, which had the standard anode and cathode compositions and a N115 PEM. The anolyte gap was filled with a fine platinum-plated tantalum screen package. The cell was operated with $1.2 \mathrm{~g} /$ min recirculating $30 \% \mathrm{H}_{2} \mathrm{SO}_{4}$ feed, first in hydrogen pump mode and then as HyS cell with 1.02-1.3x stoich $\mathrm{SO}_{2}$. As indicated in Figure 10, the hydrogen pump performance was superior to the USC-type cell having identical electrode and membrane compositions. This observation demonstrates that in the NGA configuration the overall cell resistance is not adversely affected by the addition of the anolyte gap to the PEM. As discussed further below, the PEM is the dominant factor in determining the cell resistance in the configuration and conditions studied. Further studies will be undertaken to demonstrate how increased gap thickness and sulfuric acid concentration alter the contribution of the anolyte gap to the cell resistance.

NGA-01 was then run in HyS mode at 1-2 $\mathrm{g} / \mathrm{min} 30 \% \mathrm{H} 2 \mathrm{SO}$, but only briefly, as the cell indicated some instability. The observed performance was not significantly improved over the initial NGA test at GES in 2007 $\left(1.05 \mathrm{~V}\right.$ at $\left.500 \mathrm{~mA} / \mathrm{cm}^{2}\right)$, where a thicker gap (0.07"), thicker PEM (N117), and lower temperature $\left(60^{\circ} \mathrm{C}\right)$ were used. Because there was some indication of corrosion at the ports as traces of a greenish-brown $\mathrm{SO}_{2}$ gas port effluent, the cell was run only for about 20 minutes. Through this limited testing, the performance seemed to steadily rise with time and was somewhat responsive to increased anolyte flow. Polarization scans are shown in Figure 10.

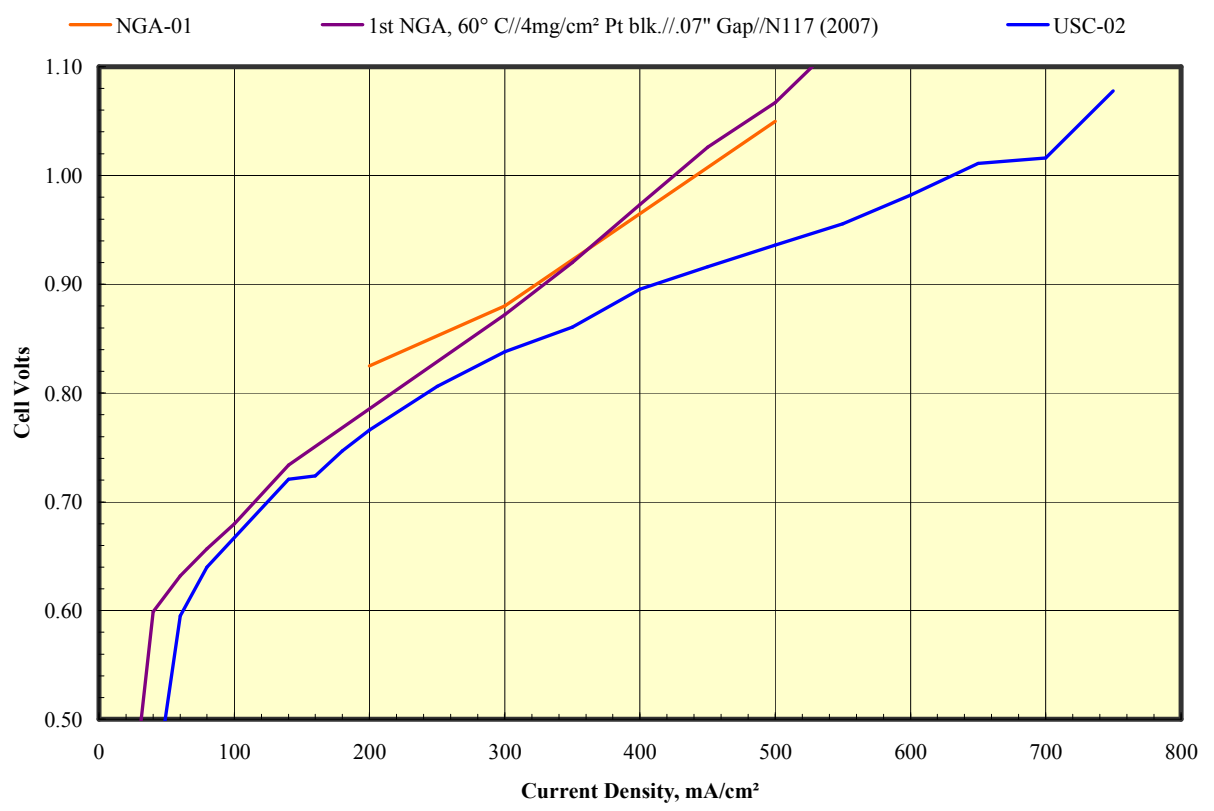

Figure 10. HyS polarization scan for Build NGA-01 compared to previous work.

The corrosion residue observed in the brief NGA-01 testing cast doubt on the suitability of one of the following cell materials: the graphite used in the anode/cathode collectors; Hastelloy B-2 used for port fittings; and/or tantalum used as the gap support. It was decided that in the subsequent build that the tantalum gap support and the Hastelloy B-2 port fittings would be replaced to eliminate the source of the corrosion. Examining the chemical and thermal compatibility needs of the support resulted in the choosing of polyvinylidene fluoride (PVDF) as the alternate gap support material. PEEK was chosen as a replacement for the port fittings for similar reasons and because of its machinability. There was also some suspicion that the poor performance observed in the HyS mode for NGA-01 was due to an electrochemical interference caused by the tantalum support. The 
PVDF package was made by overlaying and fusing strands of 0.017" PVDF monofilament (Seaguar, New York, NY) using custom tooling fabricated at GES. Figure 11 below shows a model of the jig tool; the PVDF support fabricated is shown in Figure 12.

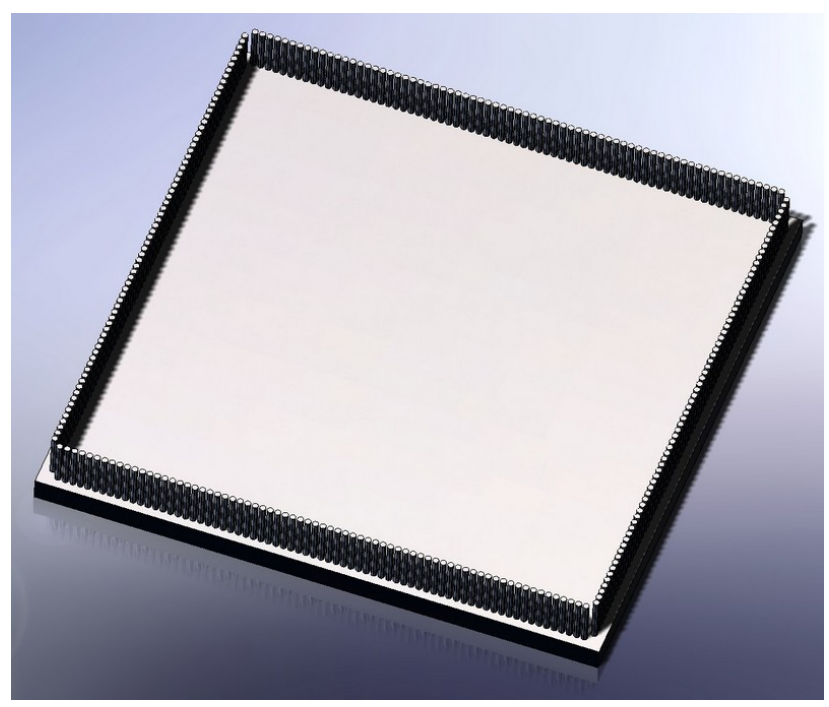

FIGURE 11. MODEL OF PVDF "WEAVING" JIG.

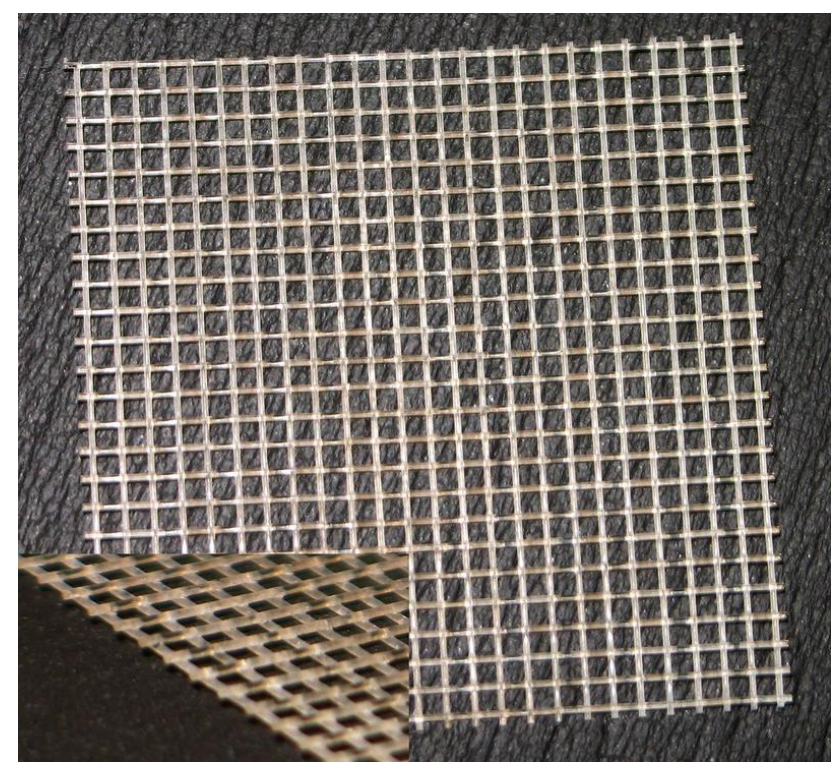

FIGURE 12. PLAN AND EDGE (INSERT) VIEW OF PVDF ANOLYTE GAP SUPPORT.

NGA-02/03. The NGA HyS electrolyzer was reassembled (NGA-02) using the PVDF filament support in place of the tantalum screen and employing the same membrane and electrode formulations as used in the previous NGA build and the USC-type builds. The original Hastelloy B-2 custom fittings for the cell's six ports were replaced with the new set machined from PEEK. Performance in hydrogen pump mode indicated higher polarization than the NGA-01 build; the lower apparent resistance of the NGA-01 build may be due to increased lateral electrical conductivity provided by the tantalum support.

Build NGA-02 was tested under HyS conditions $\mathrm{SO}_{2}$ oxidation using $1.2 \mathrm{~g} / \mathrm{min}$ recirculating flow of $31 \%$ $\mathrm{H}_{2} \mathrm{SO}_{4}$. As discussed in the hydrogen pump results, this cell configuration seems to suffer from high resistance compared to the others shown; also, the sulfuric acid concentration during this polarization scan was not measured and may have been significantly greater than $31 \mathrm{wt} \%$.

During HyS operation, NGA-02 indicated a higher cell resistance (apparent in Figure 13), but its dynamic behavior and parametric responses were similar to NGA-01. Parameter testing during operation seems to indicate that 1) the cell seemed most stable at a flow rate of $\sim 4 \mathrm{~g} / \mathrm{min}$, but tends to cool off gradually at higher flows, putting an upper limit on the steady-state performance obtainable with a reservoir of anolyte at ambient temperature; 2) the cell operated at a more consistent voltage in co-flow conditions, where $\mathrm{SO}_{2}$ and anolyte are both pumped into the cell at the same side of the cell; 3) running DI water over the cathode at $1.2 \mathrm{~g} / \mathrm{min}$ during operation did not decrease or stabilize cell polarization; 4) switching to nitrogen feed and maintaining $0.9 \mathrm{~V}$ polarization results in current of $0.55 \mathrm{~A}$ down to $0.14 \mathrm{~A}$ over the course of an hour -- this residual current is the oxidation of $\mathrm{H}_{2} \mathrm{SO}_{3}$ dissolved in the sulfuric acid. 


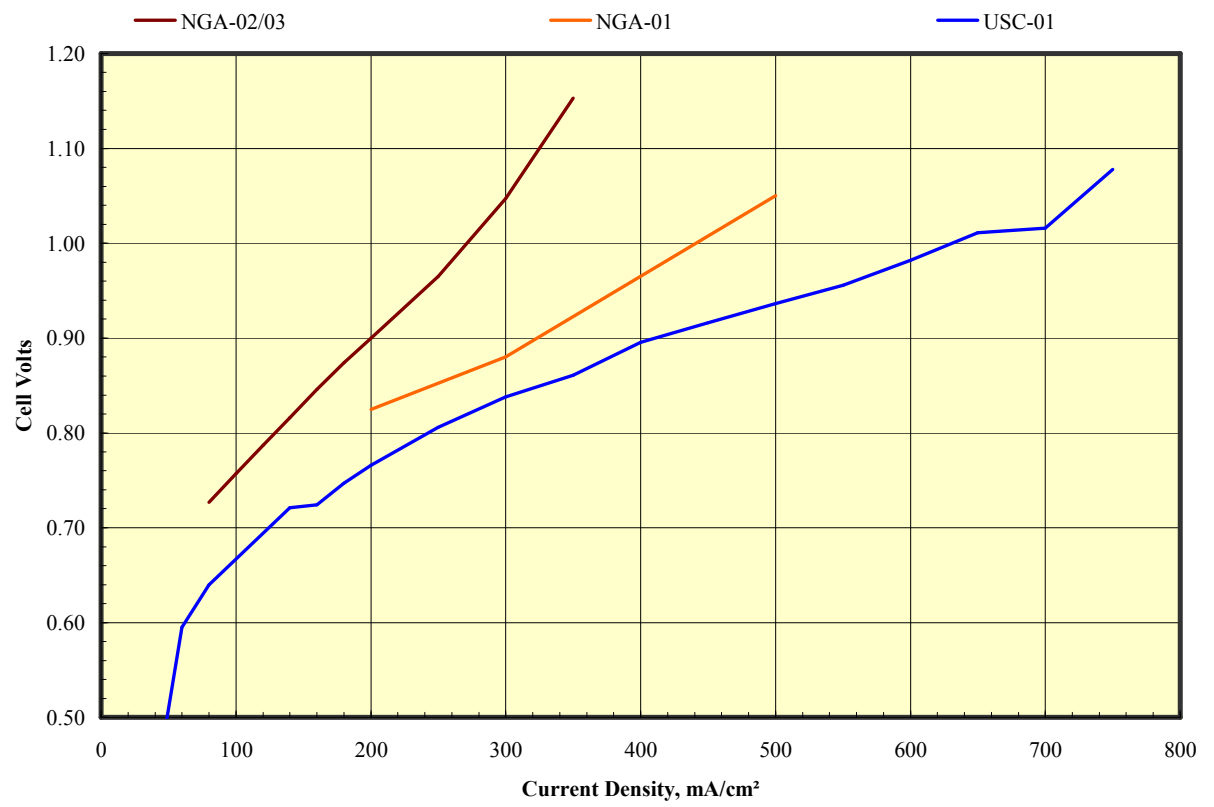

Figure 13. HyS polarization scan for NGA-02/03.

Build NGA-03 differed from the NGA-02 build only in the orientation of the gap gasket and gap support, and no apparent dependence was discerned due to this change. The absence of corrosion residue in both of these builds indicated that the PEEK material was a suitable replacement for the Hastelloy B-2 in the port fitting parts.

NGA-04. Due to the high cell polarization observed in HyS operation for the NGA-HyS cells, build NGA-04 was assembled using an "all-PTFE" anode (no Nafion). The Nafion was removed from the anode catalyst layer to test whether the ionomer may be preventing the sulfuric acid from diffusing into the bulk anolyte. The tantalum support was returned to the NGA cell as it was apparent that it was not a source of corrosion residue and that the tantalum did not interfere significantly with the anode electrochemistry. Polarization scans for NGA-04 build compared to the first NGA build (NGA-01) are shown in Figure 14, along with the second/third builds (NGA-02/03) and the USC-type electrolyzer under similar conditions. The hydrogen pump testing indicates that, despite the tantalum support, the cell resistance of this build is higher than that observed for the other builds shown -- this is presumably due to the N117 PEM. The $\mathrm{SO}_{2}$ oxidation performance was unsteady (similar to all other HyS electrolyzer cells tested), but indicated intermittent cell voltage as low as $735 \mathbf{~ m V}$ at $500 \mathrm{~mA} / \mathrm{cm}^{2}$ and, during polarization scan, performance superior all other configurations tested to this point. The performance improvement is believed to be due to the better access of sulfuric acid product to the anolyte; Nafion in the catalyst ink will reject $\mathrm{SO}_{4}^{--}$and $\mathrm{HSO}_{4}^{-}$, thereby limiting the ability of sulfuric acid to leave the anode catalyst layer. The buildup of $\mathrm{H}_{2} \mathrm{SO}_{4}$ in the catalyst layer should result in lower water activity, which has a negative impact on both the reversible anode potential and the anolyte conductivity. 


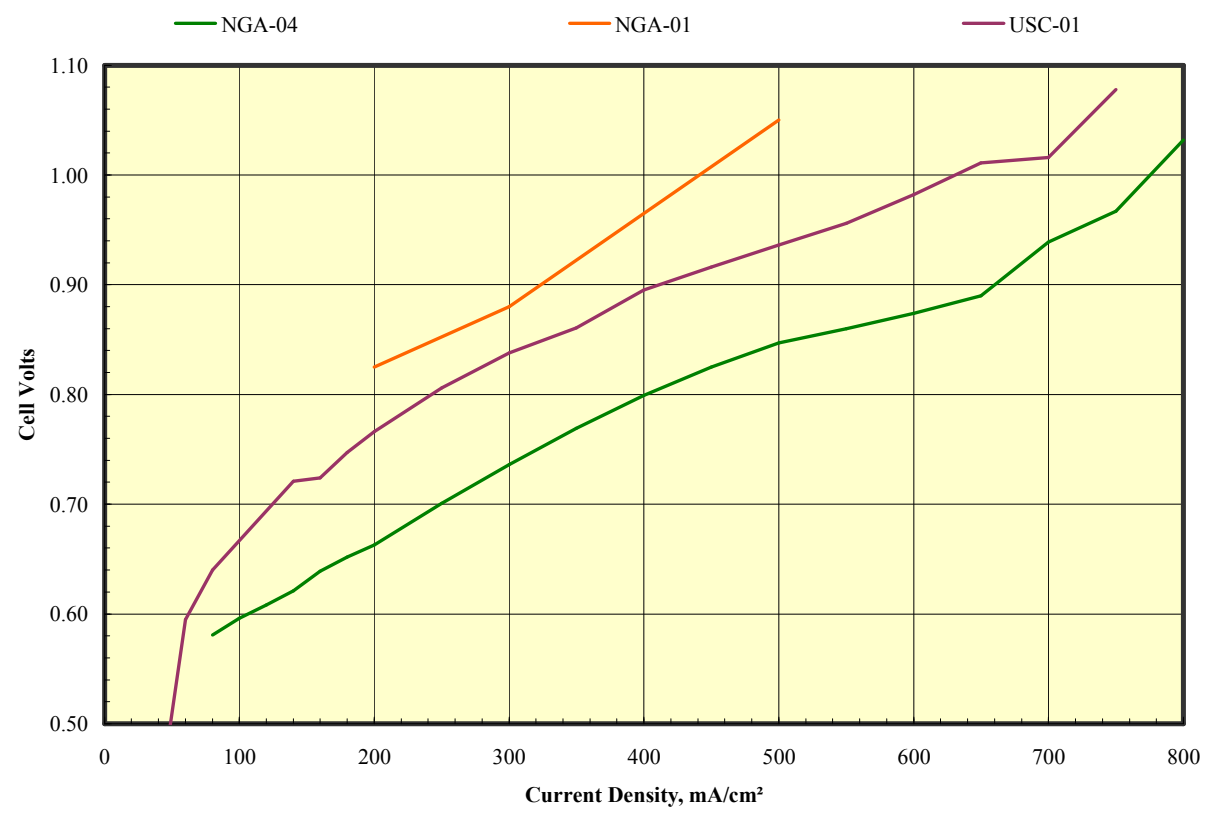

Figure 14. HyS polarization scans for Build NGA-04.

NGA-05. Build NGA-05 had a configuration identical to NGA-04, but employed N1135 PEM. The hydrogen pump testing indicates that the N1135 provides lower cell resistance than N115 and N117 (thicker PEMs), the expected result. Figure 15 shows a plot of the data on the $\mathrm{SO}_{2}$ oxidation testing of build NGA-05, which was conducted with a very high anolyte flow of $15 \mathrm{~g} / \mathrm{min}$. The cell exhibited some seepage (liquid flow from gap side to gas side) and was more sensitive to higher $\mathrm{SO}_{2}$ stoichiometry than usual, but the early polarization behavior was low and stable. Seepage is generally undesirable in narrow-gap GDE cells as it is indicative of GDE pore flooding. The seepage was presumably related to the higher flows used in this testing, though post-op evaluation indicated that there was some partial blockage of inlet ports to the gap. This partial blockage, coupled with the slight misalignment of the gap frame and anode plate anolyte supply holes, could have made for a high inlet pressure drop that may have forced some anolyte around the gasket and into the gas side, regardless of the high flow rate. The high flow rate did result in a higher steady state anolyte temperature in the reservoir, which may have caused some degradation of the pump tubing.

Figure 16 shows the formation of sulfur at the cathode side of the PEM; the patterning indicated that the rate of sulfur formation may be highest where anolyte flow is reduced. Reduced anolyte flow would result in a build of high local acid concentration, which would cause a low local current density and thus high $\mathrm{SO}_{2}$ concentration. This loss of flow may also have resulted in occlusion of the anolyte gap by gas and/or a buildup of high sulfuric acid concentration in the gap, both of which would have contributed to the apparent high cell resistance suggested in Figure 15. 


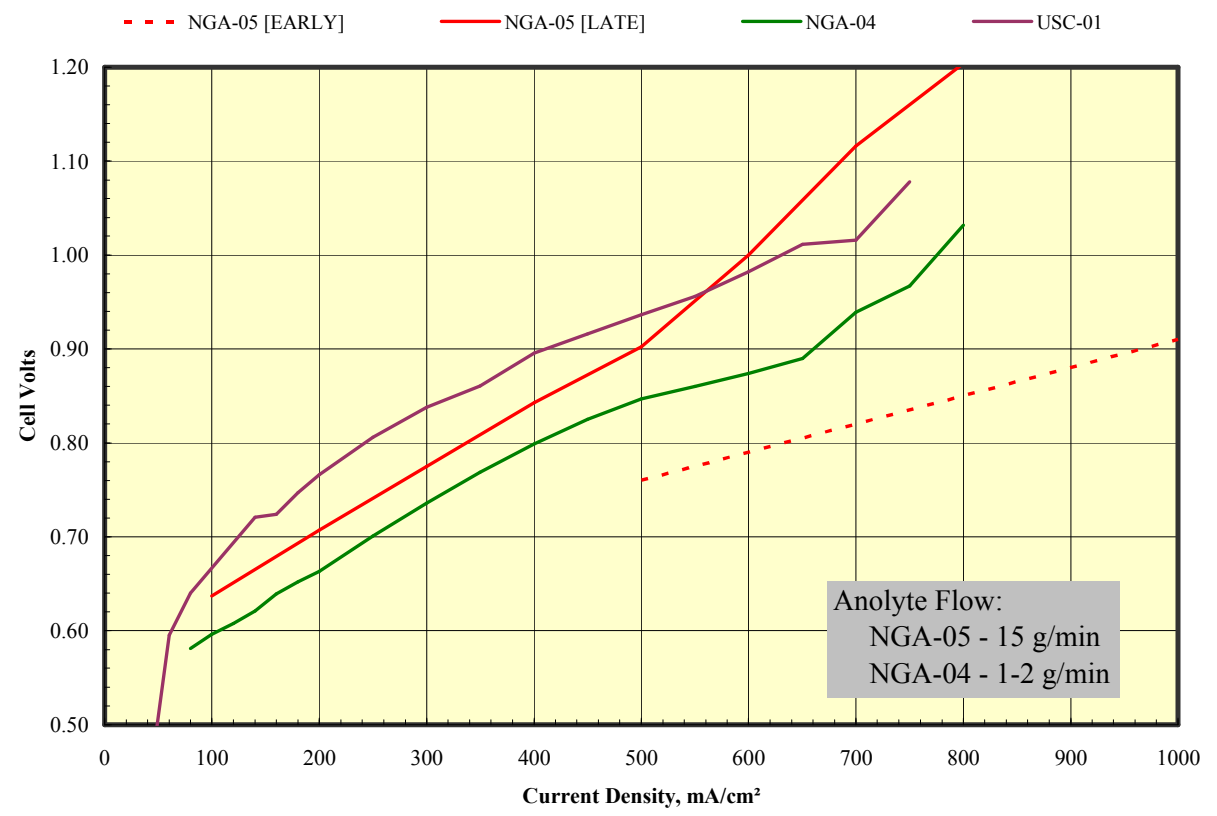

Figure 15. HyS polarization scans for Build NGA-05.

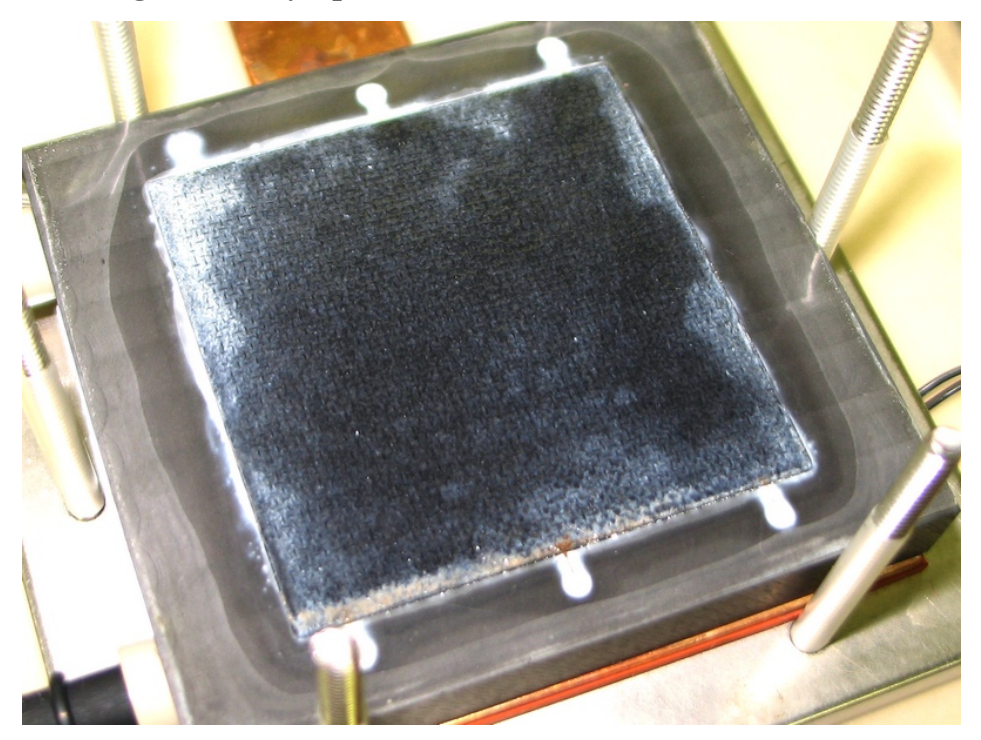

Figure 16. Membrane from Build NGA-05 showing cathode-side sulfur deposits.

NGA-06. Build NGA-06 was assembled to test a new GDE wherein the gas/contact side was treated with a Nafion/carbon layer to minimize diffusion of $\mathrm{SO}_{2}$ into the anolyte. The PEM was N117 and the cathode was identical to the previous configurations. The anode GDE was prepared by 1) spraying a carbon/PTFE microporous layer onto untreated Toray H060 followed by sintering, 2) spraying on top of this $\sim 1 \mathrm{mg} / \mathrm{cm}^{2} \mathrm{Pt} / \mathrm{C}$ + PTFE catalyst layer and drying, 3) spraying onto the opposite (gas/contact) side a layer of Nafion/carbon. The hydrogen pump testing indicated that this anode formulation performed on par with the previously tested N117 HyS MEA (NGA-04). Under conditions of $\mathrm{SO}_{2}$ oxidation, the anode rapidly evolved a seepage behavior, although operation out to $500 \mathrm{~mA} / \mathrm{cm}^{2}$ was sustainable. Figure 17 shows the performance of the NGA-06 build compared to the NGA-04 build; the difference in polarization behavior may be due to an increased cell resistance or a lower $\mathrm{SO}_{2}$ partial pressure at the anode catalyst caused by the Nafion blocking layer. Upon disassembly it was noted that the anode was completely wet through on the gas/contact side, thus allowing a 
high rate of hydraulic permeation (seepage). It is concluded that, due to the lack of seepage under $\mathrm{H}_{2}$ oxidation conditions, the generation of $\mathrm{H}_{2} \mathrm{SO}_{4}$ and/or dissolution of $\mathrm{H}_{2} \mathrm{SO}_{3}$ in the aqueous phase may have created an unstable gas/liquid boundary in this anode structure. It is also possible that very little wetproofing of the H060 was achieved during application of the carbon/PTFE microporous layer. The use of the Nafion blocking layer may be problematic, even if the Nafion/carbon layer was non-porous, because when wetted it may increase hydraulic permeation through adjacent electrode layers through condensation of an $\mathrm{SO}_{2}$-rich aqueous phase. In this case, the low rate of diffusion of $\mathrm{SO}_{2}$ compared to water inside the Nafion phase would ensure that such condensation will occur nearer to the gas/Nafion interface where the flooding behavior was observed.

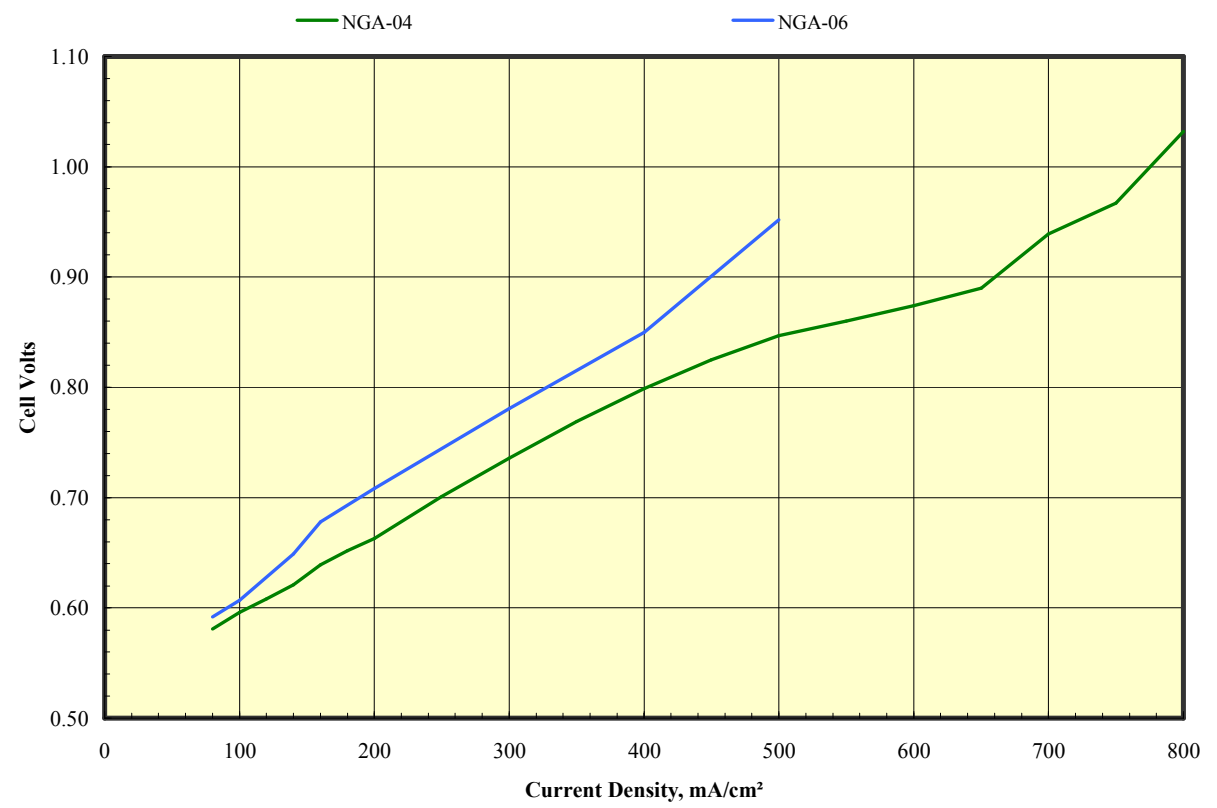

Figure 17. HyS polarization scans for Build NGA-06.

NGA-07. Build NGA-07 employed a high-loaded and heavily wet-proofed anode and N1135 PEM. The anode was prepared by coating $4 \mathrm{mg} / \mathrm{cm}^{2} \mathrm{Pt}$ black ink $/ 20 \%$ Nafion layer onto ETEK ELAT ${ }^{\circledR}$ backing. Hydrogen pump testing indicates that the anode performs slightly better than the previously tested N1135 MEA (NGA05), which is assumed to be due to the higher anode catalyst loading. Under conditions of $\mathrm{SO}_{2}$ oxidation, the anode again evolved a seepage behavior, albeit more slowly than the previous (Nafion/C front layer) anode. The cell was held at a constant current density of $500 \mathrm{~mA} / \mathrm{cm}^{2}$ at $80^{\circ} \mathrm{C}$ with $1.3 \mathrm{x}$ stoichiometry of SO2 flow and 8 $\mathrm{g} / \mathrm{min}$ flow of $30 \% \mathrm{H}_{2} \mathrm{SO}_{4}$ and, despite the seepage, the cell voltage was sustained between 0.78 and $0.89 \mathrm{~V}$ for about five hours (Figure 18). Toward the end of testing, there was virtually no liquid flow emanating from the anolyte outlet. Upon disassembly it was noted that the anode was still well wet-proofed, but that, similar to Build NGA-05, a brown residue had built up to the point of blockage on the anolyte gap frame ports. A sample of this residue was forwarded to SRNL for analysis. Significant evidence of cathode sulfur formation was visible through the PEM. 


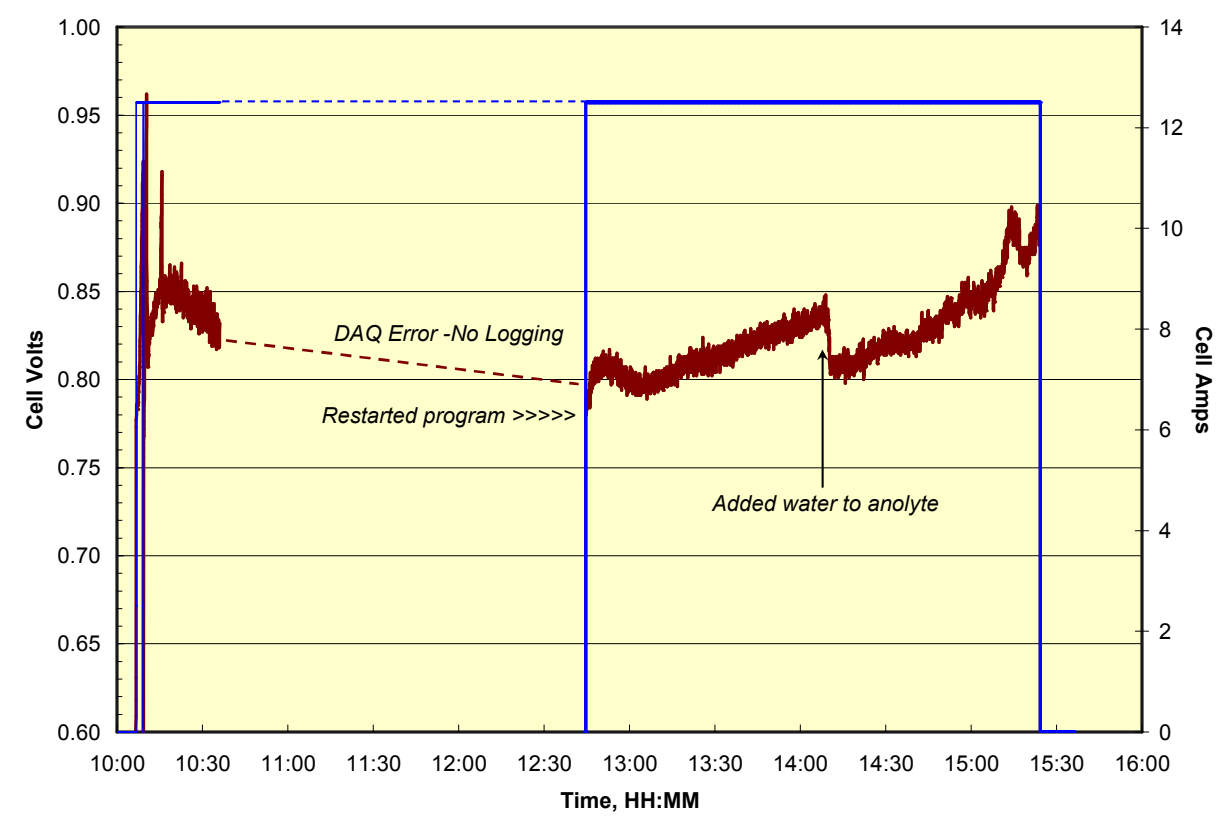

Figure 18. Timeplot of NGA-07 operating at $500 \mathrm{~mA} / \mathrm{cm}^{2}$ with $1.3 \times \mathrm{SO}_{2}$ stoichiometry.

NGA-08. Build NGA-08 had a configuration identical to the NGA-05 build. The anolyte gap frame ports were cleaned thoroughly of the brown deposits which were causing clogging. A PTFE peristaltic tubing pump was used in place of the Neoprene version to determine whether the Neoprene tubing was a source of the clogging material. Hydrogen pump performance (not shown) was oscillatory, which likely indicates that the anode was poisoned by a sulfur species that may have been resident in the cell hardware prior to assembly. Under conditions of $\mathrm{SO}_{2}$ oxidation, the cell was operated continuously at $500 \mathrm{~mA} / \mathrm{cm}^{2}$ with $\sim 8 \mathrm{~g} / \mathrm{min}$ anolyte flow, where it exhibited $0.78-1.05 \mathrm{~V}$ polarization; seepage became heavy after about $1 \mathrm{hr}$ operation on $\mathrm{SO}_{2}$. Upon disassembly it was noted that the anode was still well wetproofed, and that no brown residue had built up on the anolyte gap frame ports. It was originally assumed that the Neoprene peristaltic pump tubing was the source of clogging residue, though the cleaning of the ports did result in the removal of some fine FEP fibers that were left over from the original machining process of the gap frame. The cause of seepage was considered at this point to be related to anolyte head pressure.

NGA-09. Build NGA-09 had identical configuration to the NGA-04 build ("all-PTFE" style anode, standard Ta screen gap support, N117 PEM, and the standard Pt/C cathode). This cell was heated to $80^{\circ} \mathrm{C}$, pumped with $\sim 8 \mathrm{~g} / \mathrm{min}$ flow of $\sim 31 \% \mathrm{H}_{2} \mathrm{SO}_{4}$ (recirculating) using the PTFE peristaltic pump, but not wired to the power supply. Nitrogen was supplied to the cathode side to flush $\mathrm{SO}_{2}$ to a scrubber. Hydrogen was introduced to the gas side of the anode GDE at $30 \mathrm{sccm}$ for $\sim 1 \mathrm{hr}$, over the course of which time a low rate of seepage evolved. $\mathrm{SO}_{2}$ was then introduced at $30 \mathrm{sccm}$, and over the course of $\sim 1 \mathrm{hr}$ the seepage continued at a slightly increased rate. The test was inconclusive with respect to how gas type affected the stability of the gas-liquid interface, but does show that the GDEs as fabricated are not completely resistant to seepage during non-operation under these conditions. The observation of light through small holes in the catalyst layer of the as-prepared anode GDEs corroborates the suggestion that the seepage is related to the GDE morphology.

Further testing on NGA-09 was done utilizing the PTFE peristaltic pump at $8 \mathrm{~g} / \mathrm{min}$, this time with a manometer connected to the cell at the anolyte inlet to measure cell head pressure. It was observed that the anolyte head pressure at the inlet was $\sim 12 \mathrm{iwc}$; this was decreased to 2.5 iwc by lowering the anolyte return tubing outlet to bottom of the anolyte reservoir, thus allowing siphon to alleviate the head created in this tubing as it run from the cell up to the top of the reservoir cap. Figure 19 shows the relative stability of NGA-09 at $500 \mathrm{~mA} / \mathrm{cm}^{2}$ and $1.1 \mathrm{x}$ stoichiometry $\mathrm{SO}_{2}$ flow, the steady rise in voltage due to the gradual increase in reservoir anolyte $\mathrm{H}_{2} \mathrm{SO}_{4}$ concentration. It was observed during this test that NGA-09 exhibited a markedly lower rate of seepage. The sensitivity of the cell to anolyte head pressure was noted, and monitoring and control (where possible) was incorporated into subsequent testing. 
SRNL-OS-2009-00070, REVISION 0

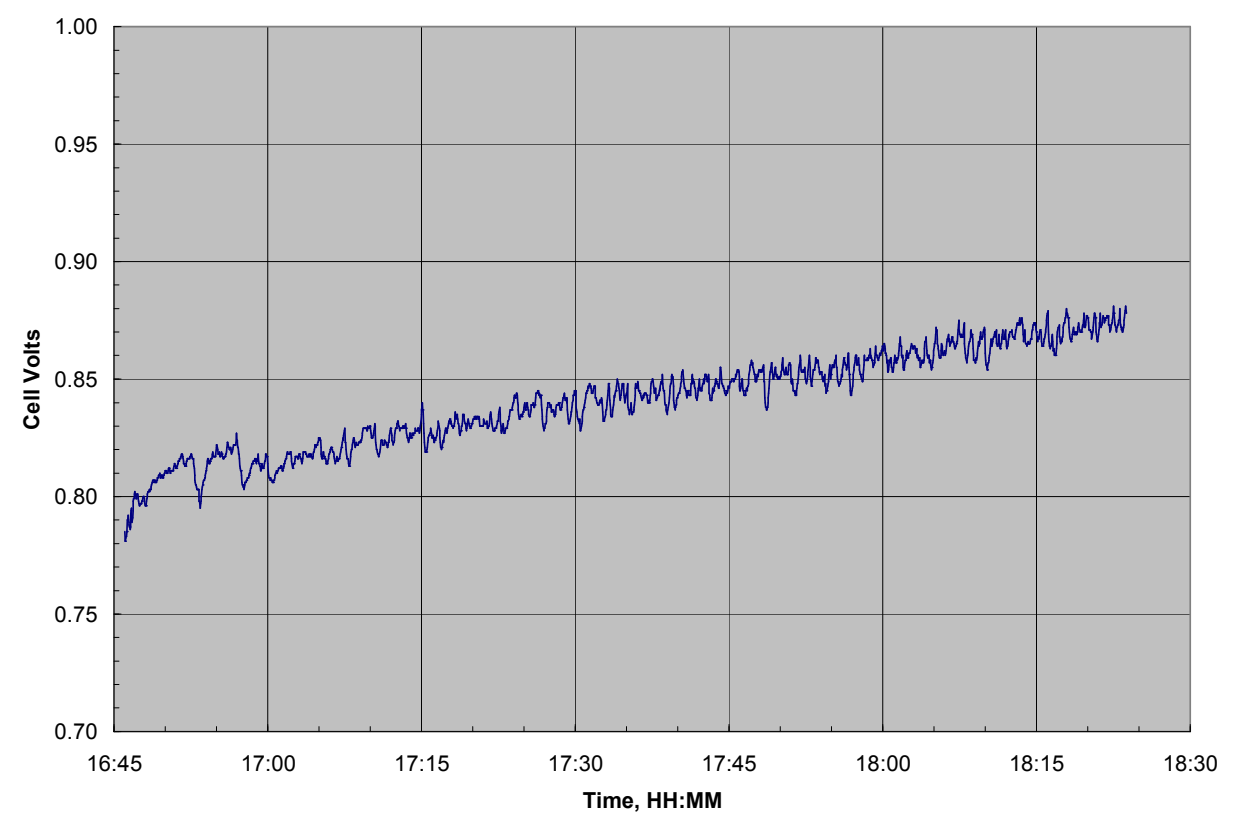

Figure 19. Timeplot of NGA-09 operation at $500 \mathrm{~mA} / \mathrm{cm}^{2}$.

NGA-10. Build NGA-10 was assembled and tested, having a configuration similar to the $-05 /-07 /-08$ builds (standard Ta screen gap support, N1135 membrane, and the standard Pt/C cathode), but including a new anode formulation having a flocced/vacuum cast layer. This flocced layer was prepared with a high PTFE content and particle density such that a robust wetproofing and low porosity are imparted. These characteristics are presumed to be helpful in the control of anolyte seepage. The flocced layer was formed by casting a flocculate of carbon and PTFE ( $50 \mathrm{wt} \%$ ) onto a substrate at a loading of $2 \mathrm{mg} / \mathrm{cm}^{2}$. The casted layer was dried and pressed onto a wetproofed Toray H060 electrode substrate. A low-density (standard) microporous layer $\left(1 \mathrm{mg} / \mathrm{cm}^{2}\right.$ carbon $/ 50 \%$ PTFE) was then sprayed onto the flocced layer, followed by the catalyst layer $\left(1 \mathrm{mg} / \mathrm{cm}^{2} \mathrm{Pt} / \mathrm{C}, 33 \%\right.$ PTFE).

Cell performance for NGA-10 is shown in Figure 20: the hydrogen pump performance was worse than that observed for the previous $\mathrm{N} 1135$ builds, which may reflect increased resistance of the thicker catalyst/carbon layers. Under conditions of $\mathrm{SO}_{2}$ oxidation, the cell was operated at $500 \mathrm{~mA} / \mathrm{cm}^{2}$, where it exhibited $0.82-0.95 \mathrm{~V}$ polarization. The cell performance was better at $6.4 \mathrm{~g} / \mathrm{min}$ than at lower $(4 \mathrm{~g} / \mathrm{min})$ and higher $(9 \mathrm{~g} / \mathrm{min})$ flows. The anolyte inlet pressure was maintained between 6 and 10 iwc and significant seepage was not observed over the course of $4.5 \mathrm{hrs}$ of $\mathrm{SO}_{2}$ oxidation testing. 
SRNL-OS-2009-00070, REVISION 0

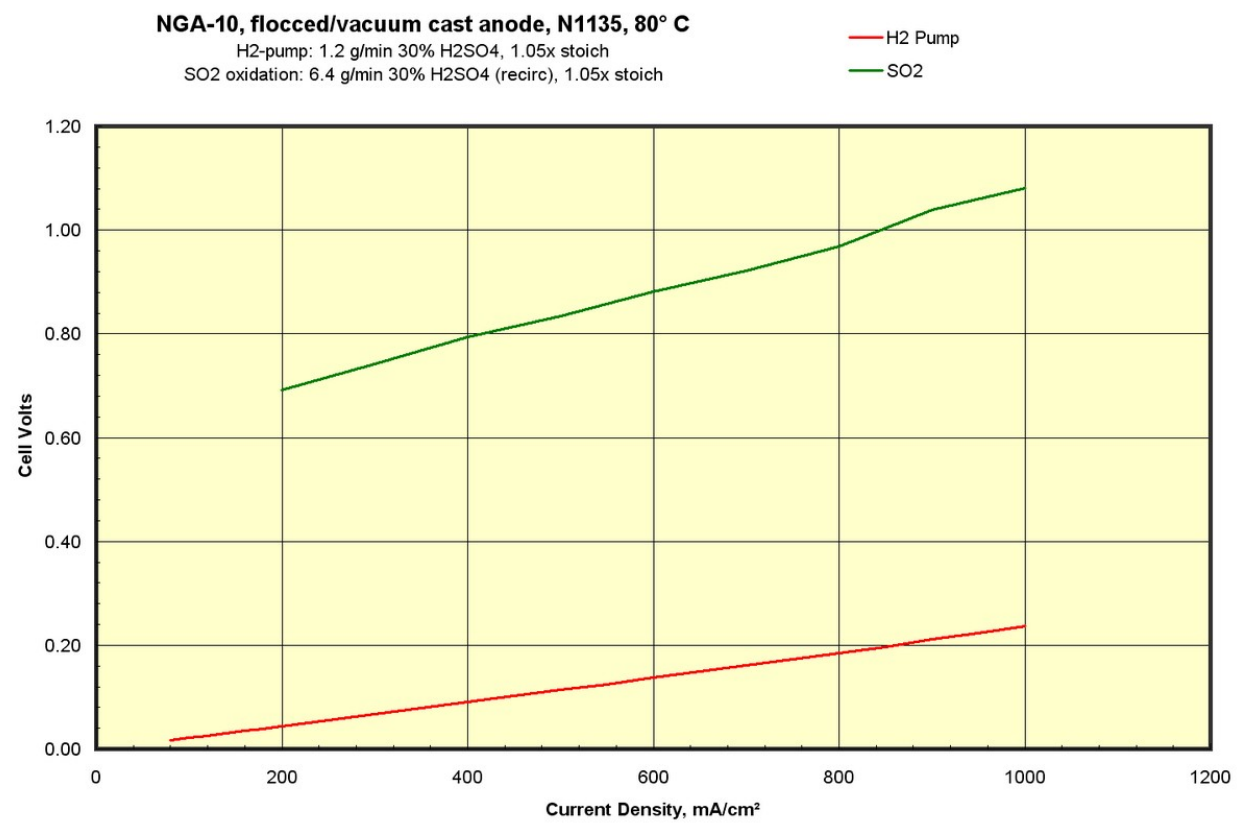

Figure 20. Polarization performance of NGA-10, which utilized a flocced/vacuum cast anode for seepage prevention.

NGA-11 and NGA-12. Build NGA-11 was assembled and tested, having a configuration similar to the -05 builds (all-PTFE anode, N1135 membrane, and the standard Pt/C cathode), but using a serpentine gap plate having a thickness of 0.063 ". The serpentine gap was incorporated to improve the flow distribution of anolyte across the cell active area, which will presumably provide improved stability. The serpentine structure precludes the use of the Ta gap support, so anolyte was allowed to fully fill the channels. This cell was tested at $80^{\circ} \mathrm{C}$ for performance under $\mathrm{H}_{2}$-pump operation. The cell was rebuilt using the same membrane/cathode assembly, but with new anode and the thinner .032" serpentine gap support (Build NGA-12). Performance under $\mathrm{H}_{2}$-pump was then repeated for NGA-12. The polarization results (Figure 21) indicate that the serpentine channels are more restrictive of anolyte conductivity and/or anode catalyst utilization compared to the .032" standard gap/Ta screen support configuration (NGA-05). As would be expected with a shorter electrolyte path between the anode and the PEM, the .032" serpentine support exhibited a lower apparent cell resistance that the .063" support. Build NGA-12 was operated in $\mathrm{HyS}$ mode at $80^{\circ} \mathrm{C}$ with $2.6 \mathrm{~mL} / \mathrm{min} 30 \% \mathrm{H}_{2} \mathrm{SO}_{4}$ in recirculating mode. The performance exhibited deterioration similar to certain previous tests, and the polarization behavior was similar (Figure 22) to that observed in the "all-PTFE"/N1135 configuration (NGA-05) after the onset of seepage. The appearance of seepage and blow-through was noted within the first 30 min of operation in HyS mode. The anolyte inlet pressure was observed to increase significantly, from $\sim 10$ iwc to $\sim 20$ iwc within the same time period. On disassembly it was observed that the ports of the gap support were clogged with a dark brown residue that resembled catalyst/carbon that may have sloughed off of the GDE. Though, as discerned through previous analysis conducted at SRNL, a precipitate is generated in the GES NGA electrolyzer under certain conditions that seems to originate from PEEK. Ways were considered to increase the stability of the "allPTFE" catalyst layer so that catalyst particles are not as easily shed into the anolyte. It was discerned upon disassembly from examining the anode GDE and the serpentine support that a significant amount of anode catalyst was imprinted into the FEP of the support plate and thereby removed from the GDE on decompression. The appearance of a sulfur layer is suggested in the image of the MEA (Figure 23); the pattern of the coloration indicates that where the "lands" of serpentine gap insert lay up against the PEM there is a significant attenuation of whatever transport process or other effect is responsible for the sulfur layer formation. 
Serpentine Anolyte Gap - Dependence on Gap Thickness

$80^{\circ} \mathrm{C}, 1-2 \mathrm{~g} / \mathrm{min} 30 \% \mathrm{H}_{2} \mathrm{SO}_{4}, \mathrm{H}_{2}$ Pump, All-PTFE An./N1135/Std. Cath.

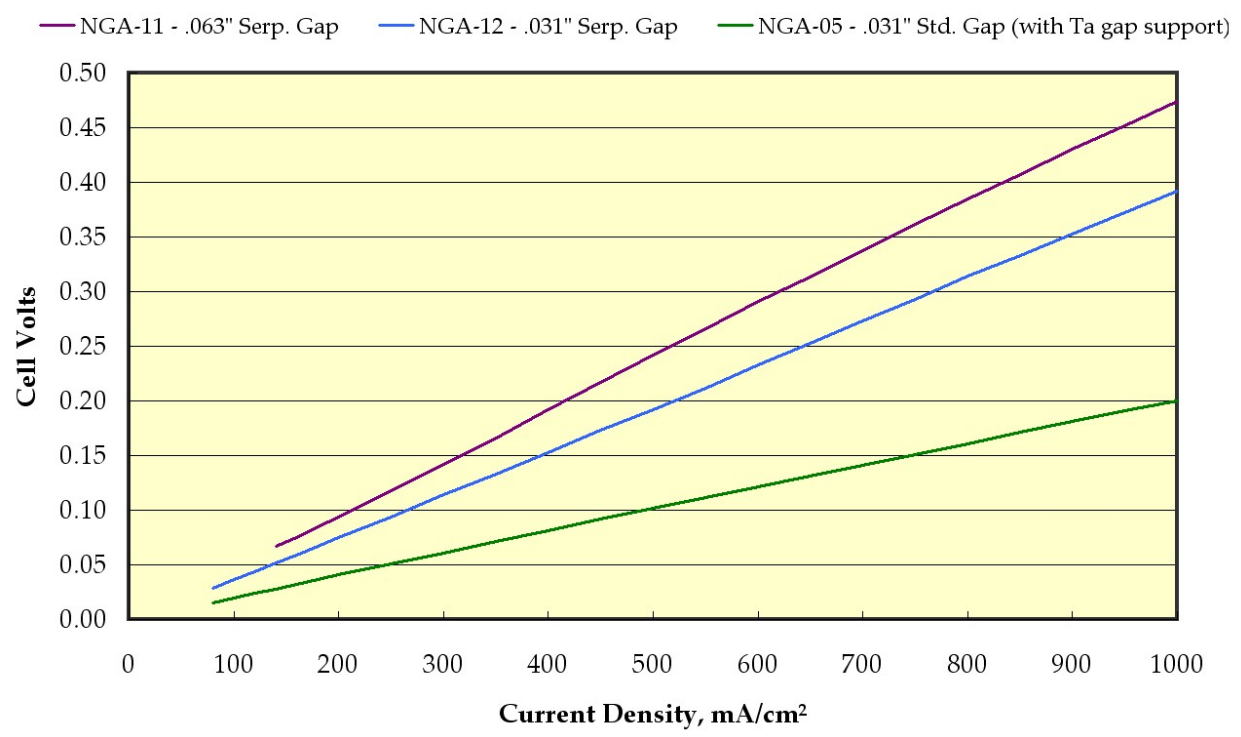

Figure 21. Hydrogen pump testing of NGA-11 and NGA-12 builds, as compared to "open gap" equivalent build NGA-05.

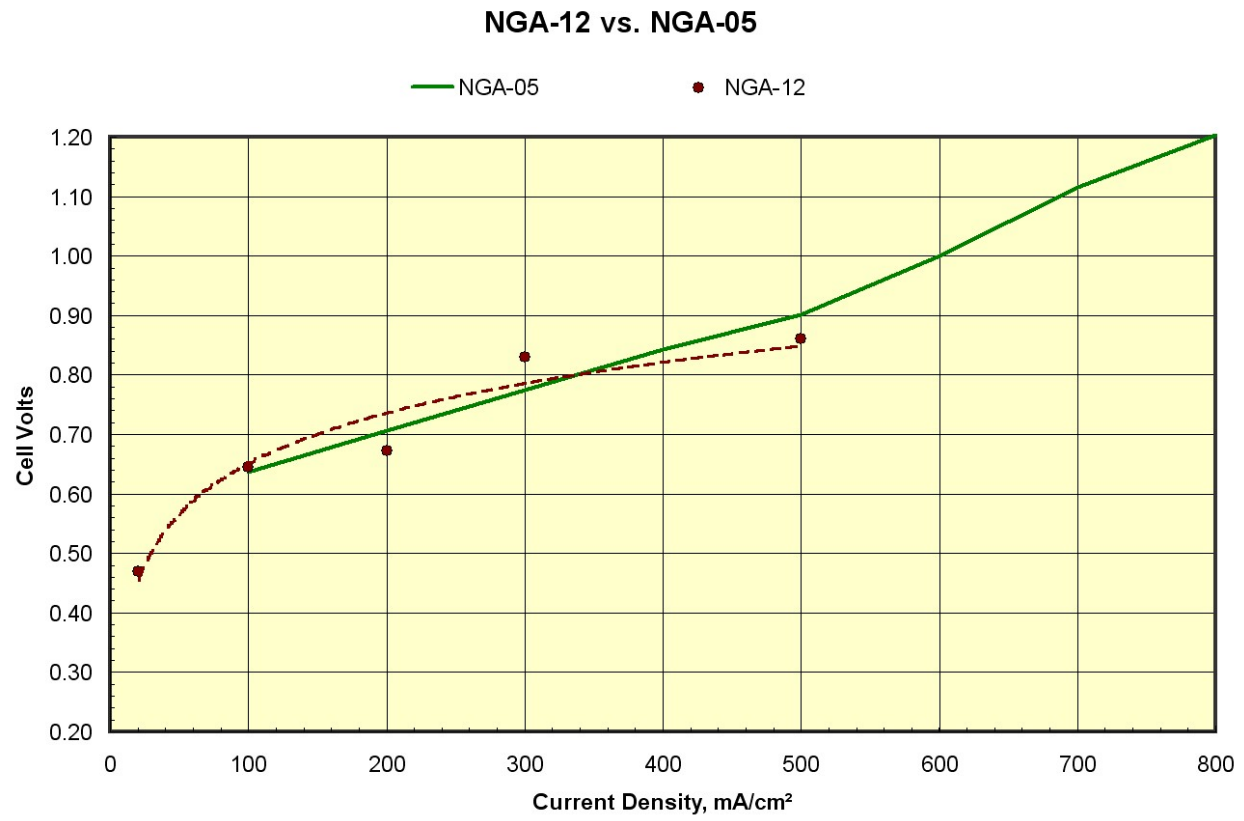

Figure 22. SDE performance of NGA-12 vs. NGA-05. 


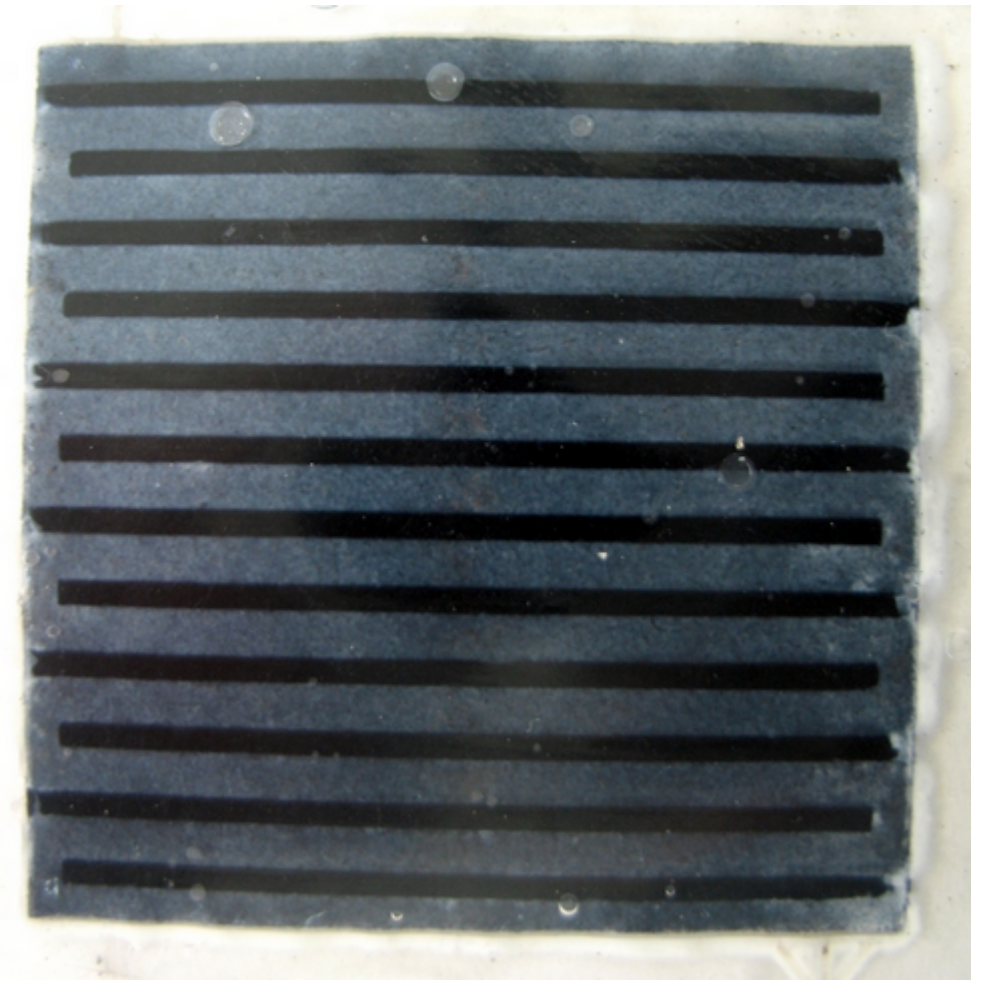

Figure 23. Photograph from the anode side of the MEA from NGA-12 after disassembly, showing regions of differential sulfur layer formation on the cathode.
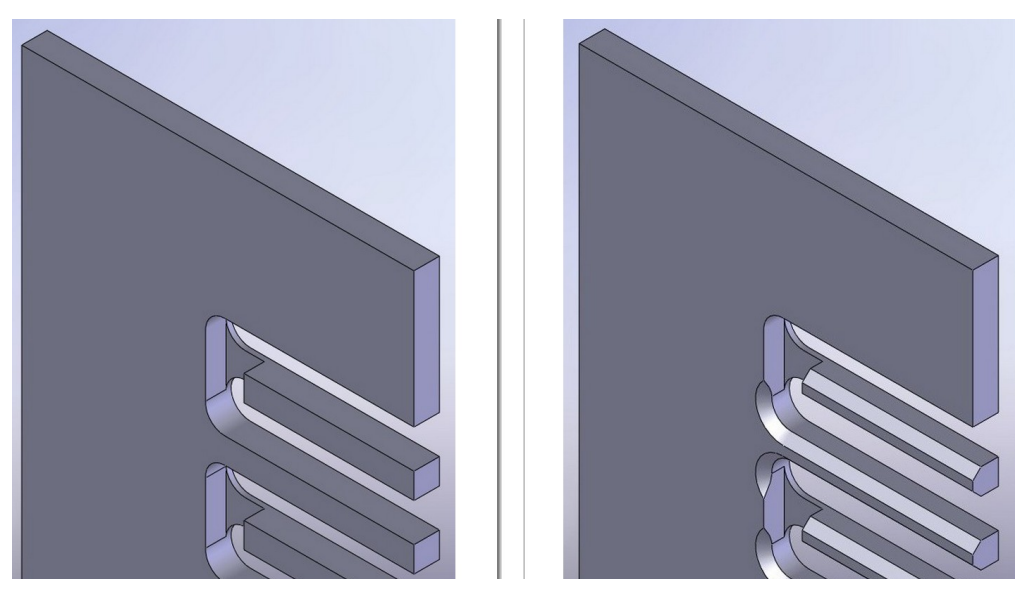

Figure 24. Model (section) view of proposed chamfering of serpentine flowfield to maximize electrolyte access; the flowfield used in testing is shown to the left.

The application of a chamfer to the electrode-side channel edges should allow more direct contact between electrolyte and catalyst layer and provide a larger electrolytic pathway (see Figure 24). Both of these effects should improve the observed polarization of the anode in the serpentine anolyte gap cell.

\section{General Observations of NGA Electrolyzer Performance}

As demonstrated in the testing program, the NGA electrolyzer design employed by GES has excellent conductance and good electrochemical efficiency for an ambient pressure system, but was plagued regularly by seepage issues. A significant effort was focused on addressing the seepage through anode modifications, but it 
was discovered late in the program that blockage of the small anolyte port vias, which connect the port holes to the gap, was the prime antagonist in the seepage behavior as it created high anolyte backpressures that could force liquid through pores in the anode GDE. The sources of particulate blocking material include Neoprene rubber from the peristaltic pump, sloughed or loose catalyst ink from the anode GDE, and corrosion products from the PEEK cell fittings. All of these sources are likely to be mitigated through careful system hardware and electrode/gap support design.

All HyS electrolysis technologies share a dependence of electrolytic conductivity on sulfuric acid strength. As recently discussed by Gorensek et $a l^{2}$, the thermodynamic overpotential of the HyS electrolyzer also has a strong (Nernstian) dependence on the concentration of $\mathrm{H}_{2} \mathrm{SO}_{4}$ generated at the anode. Thus a careful consideration of the NGA operating potential and acid strength is warranted. Figure 25 shows the outlet sulfuric acid concentration at $500 \mathrm{~mA} / \mathrm{cm}^{2}$ for the single-pass $30 \% \mathrm{H}_{2} \mathrm{SO}_{4}$-fed NGA at various anolyte inlet flows and net water transport numbers. The net water transport number corresponds to the number of water molecules per proton that are swept from the anolyte through the PEM to the cathode. Whereas there will be a strong diffusive force to bring water back to the anode side, the electroosmotic effect demands that a net flux of water be maintained. A careful measurement of the net water flux was not undertaken in this study, but it can be seen from Figure 25 that the anolyte flow is a much stronger determinant of the product anolyte concentration. The high Nernstian overpotential and low gap/PEM conductivity imparted at high average acid concentration are partial explanations for the high observed cell voltages in early testing, where anolyte in flows were maintained at $1-5 \mathrm{~g} / \mathrm{min}$.

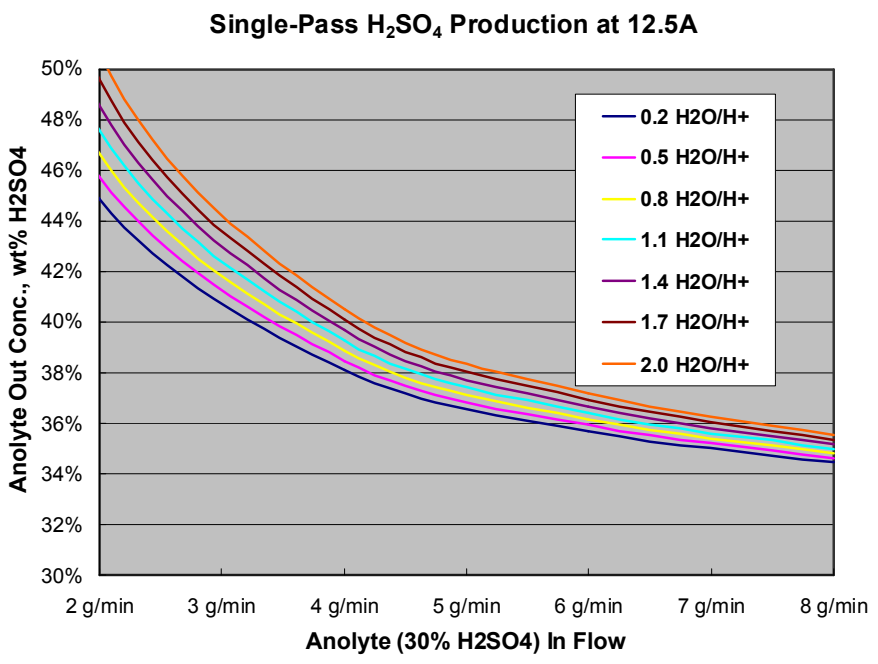

Figure 25. Calculated acid concentration in anolyte produced at $500 \mathrm{~mA} / \mathrm{cm}^{2}$ in the NGA electrolyzer at different water transport rates and $30 \% \mathrm{H}_{2} \mathrm{SO}_{4}$ anolyte in flowrates.

It is important to characterize the NGA cell in the context of the other gas fed technique, the direct feed approach developed at USC. In both cells, gaseous $\mathrm{SO}_{2}$ is provided via a flowfield to the anode GDE that interfaces electrolytic media on the other side. In the NGA cell, waters of reaction and PEM hydration are provided, in the form of aqueous sulfuric acid, to the gap between the anode GDE and the PEM. In contrast, the USC cell relies on water diffusion (or hydraulic permeation when high cathode pressure is maintained) through the PEM to satisfy the reaction and PEM hydration needs. This mechanism enforces an upper limit to the kinetic capabilities of water supply to the HyS anode. These transport limitations are rigorously described by Staser et al. ${ }^{3,4}$ with respect to the diffusion, osmotic and permeation kinetics of water in PEMs. As shown in

2 "A thermodynamic analysis of the $\mathrm{SO}_{2} / \mathrm{H}_{2} \mathrm{SO}_{4}$ system in $\mathrm{SO}_{2}$-depolarized electrolysis" M.B. Gorensek, J.A. Staser, T.G. Stanford and J.W. Weidner, Int. J. of Hyd. Energy, 34 (15), 6089-6095 (2009).

${ }^{3}$ J.A. Staser, J.W. Weidner, "Effect of Water Transport on the Production of Hydrogen and Sulfuric Acid in a PEM Electrolyzer” J. Electrochem. Soc. 156 (1) B16-B21 (2009). 
Figure 26, when the water diffusion to the anode cannot keep pace (at high current density) with the water consumption needs of the $\mathrm{SO}_{2}$ oxidation reaction and sulfuric acid hydrolysis, the high sulfuric acid concentration causes a deterioration of USC cell performance. By comparison it is also shown in Figure 26 that the NGA cell maintains a more linear behavior at high current density as the water delivery needs of the anode are more adequately satisfied. This fact implies that the NGA configuration is more amenable to careful management of the anolyte concentrations at the inlet, which should provide superior control over the HyS electrolysis process at the utility scale.

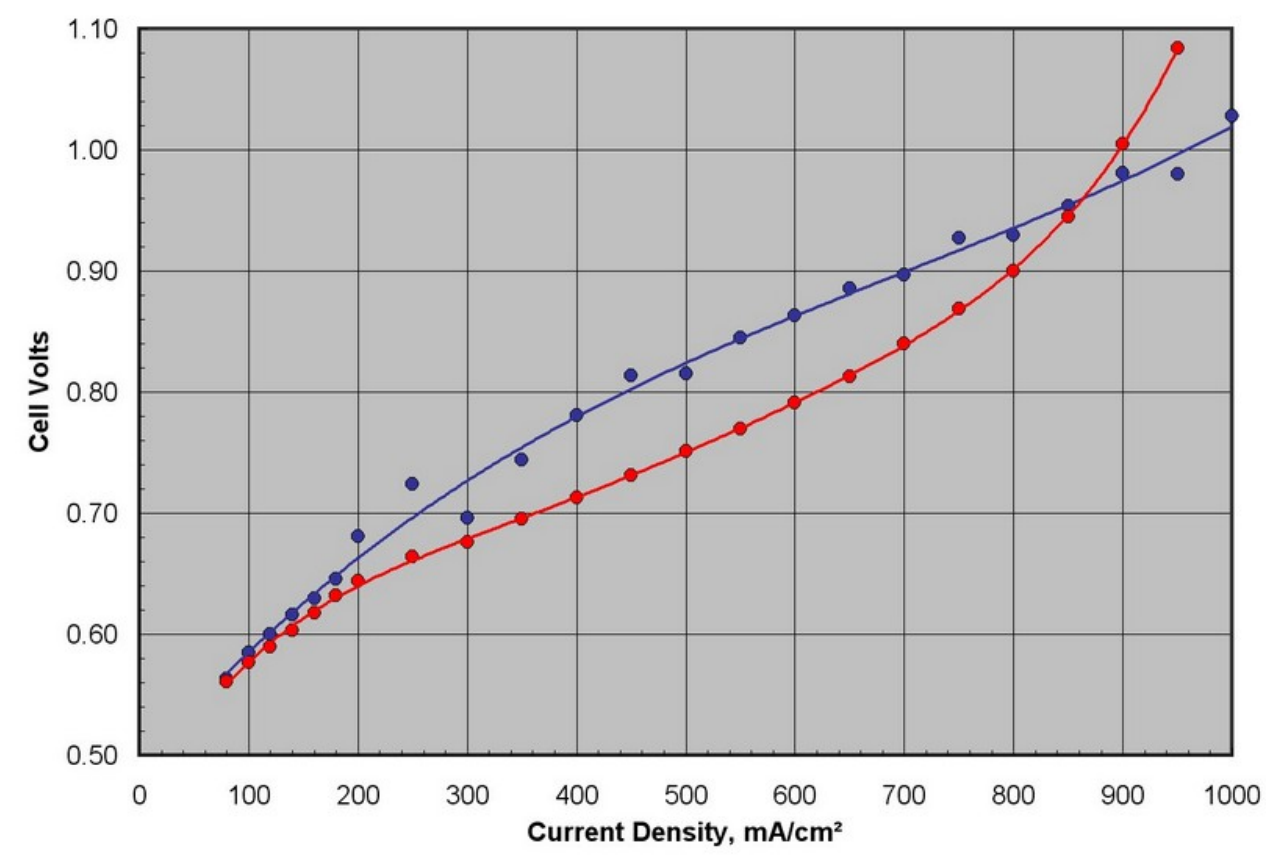

Figure 26. Comparison of observed performance between NGA-13 (blue line) and direct-feed (USC-type, red line) electrolyzer at $80^{\circ} \mathrm{C}$; both MEAs use Nafion 1135 membrane.

Figure 27 shows projected iR losses due to the serial electrolytic components of the NGA electrolyzer, the anolyte gap and the PEM. The resistivity of Nafion 1100EW was measured at GES as a function of temperature and sulfuric acid concentration, and the sulfuric acid resistance is calculated from literature conductivity data. It is clear that, under the nominal conditions employed in the NGA electrolyzer work, the $1 / 32$ " gap is a significantly smaller contributor to the overall iR drop (resistive loss) than the PEM. For instance, at $40 \%$ $\mathrm{H}_{2} \mathrm{SO}_{4}$, the iR drop in the narrow gap $(28 \mathrm{mV})$ is roughly $40 \%$ that of the PEM $(78 \mathrm{mV})$. Though the NGA electrolyzer has this serial gap resistance and the liquid feed and direct feed electrolyzers do not, the gap conductivity remains significantly lower at higher sulfuric acid concentrations. This bodes well for NGA electrolysis, especially if the NGA can be demonstrated at narrower gaps.

${ }^{4}$ J.A. Staser, J.A., K. Norman, C.H. Fujimoto, M.A. Hickner, J.W. Weidner, "Transport Properties and Performance of Polymer Electrolyte Membranes for the Hybrid Sulfur Electrolyzer" J. Electrochem. Soc. 156 (7) B842 B847 (2009). 


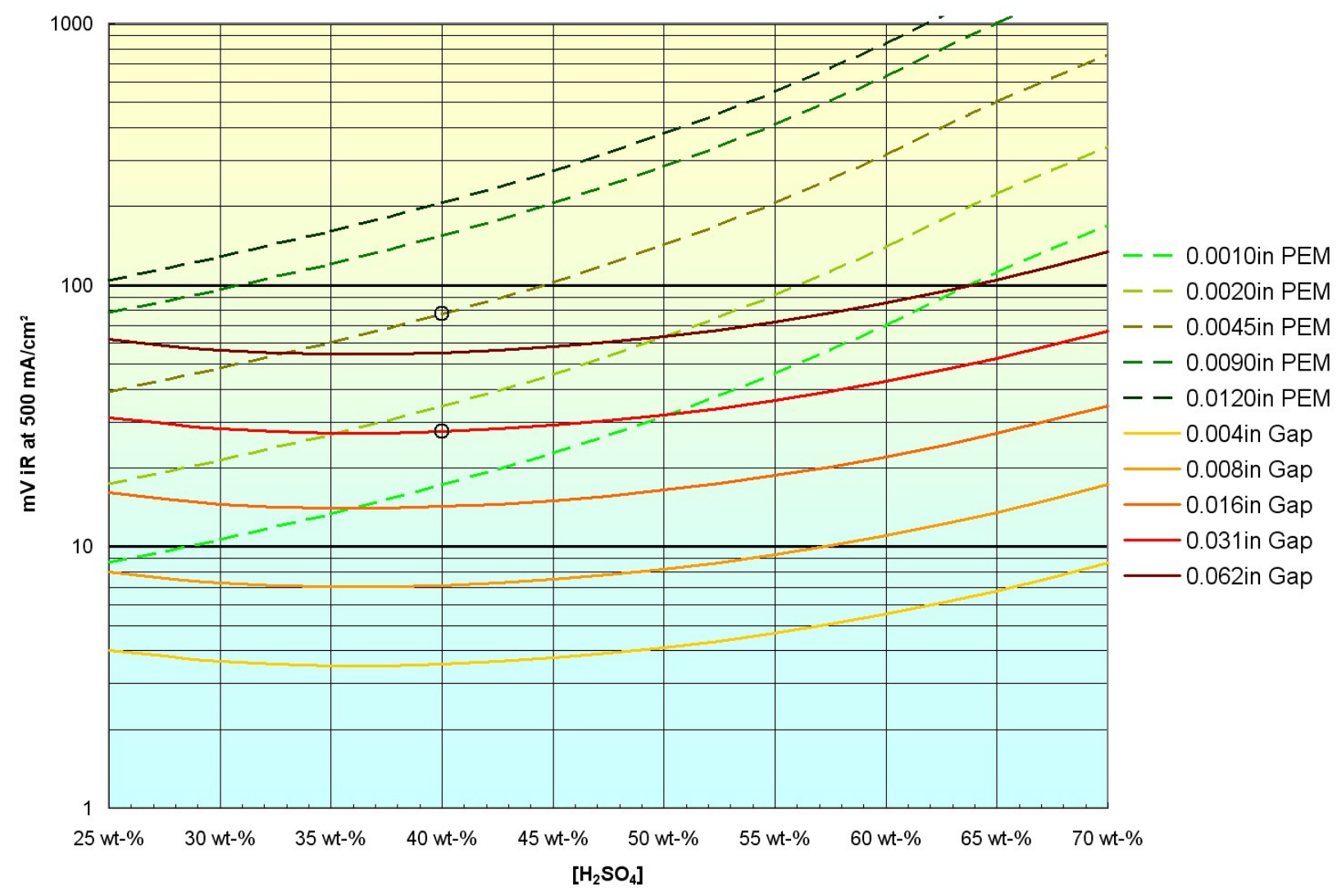

Figure 27. Comparison of projected iR voltage loss in the NGA electrolyzer at varying concentration of anolyte, gap thickness, and PEM thickness. The nominal NGA-13 operating configuration is denoted by the black circles (1/32" gap, $\mathrm{N} 1135$ membrane, $\left.40 \% \mathrm{H}_{2} \mathrm{SO}_{4}\right)$.

In this regard it is important to point out that, in the serpentine anolyte gap dependence data (Figure 21), these projections are well reflected. By replacing the 0.031 "gap/Ta support (NGA-05) with the 0.031" serpentine frame (NGA-11), the apparent cell resistance (as determined by the slope of the hydrogen pump polarization scans) doubled. This increase can be justified by the occlusion of $40 \%$ of the electrolyte paths (acid gap and PEM) effected by the plastic lands of the serpentine frame. The absence of the Ta support in the serpentine builds results in offsetting effects: the Ta screen also occluded electrolytic conduction pathways, but also provided support to the GDEs in the gap that ensured good ohmic contact with the current collectors. In doubling the serpentine gap thickness by going to the 0.062 " frame, the observed cell resistance increased only $20 \%$, indicating the relatively modest contribution the gap resistance makes compared to overall cell resistance. In other words, the PEM is still the dominant resistive cell element under these conditions.

\section{Endurance Testing}

A critical aspect of the NGA technology demonstration is the electrolyzer performance during extended testing. To prepare the system for long operation runs, a means of maintaining sulfuric acid concentration was implemented. The HyS electrolyzer system was fitted with a conductivity probe, which, in conjunction with a control algorithm and a switched water pump, facilitated the maintenance of constant acid strength.

The conductivity transmitter was a Honeywell Model APT-2000-TC-H-00 fitted with a PFA-encased toroidal conductivity probe. The device measures up to $5 \mathrm{~S} / \mathrm{cm}$ and was installed into a $0.5 \mathrm{~L}$ PFA reservoir that was stirred and warmed upon a ceramic hotplate having independent temperature control. A software-based control algorithm dosed the reservoir with DI water to maintain constant conductivity as sulfuric acid is accumulated in the anolyte. The modified HyS electrolyzer system is pictured in Figure 28. The mass flow controller, temperature controllers, conductivity transmitter, and manometer are shown to the left out side the hood. From left to right inside the hood are shown: the cathode separator; scrubber caustic pump; cell (with scrubber 
assembly behind; anolyte reservoir with conductivity probe inside and stirring hotplate beneath. To the right of the hood are the DI water reservoir (for adding to anolyte), and DI water adding pump, (on top of) anolyte pump, (on top of) DAQ board (for cond. meas. and water pump actuation), (on top of) electrolyzer power supply.

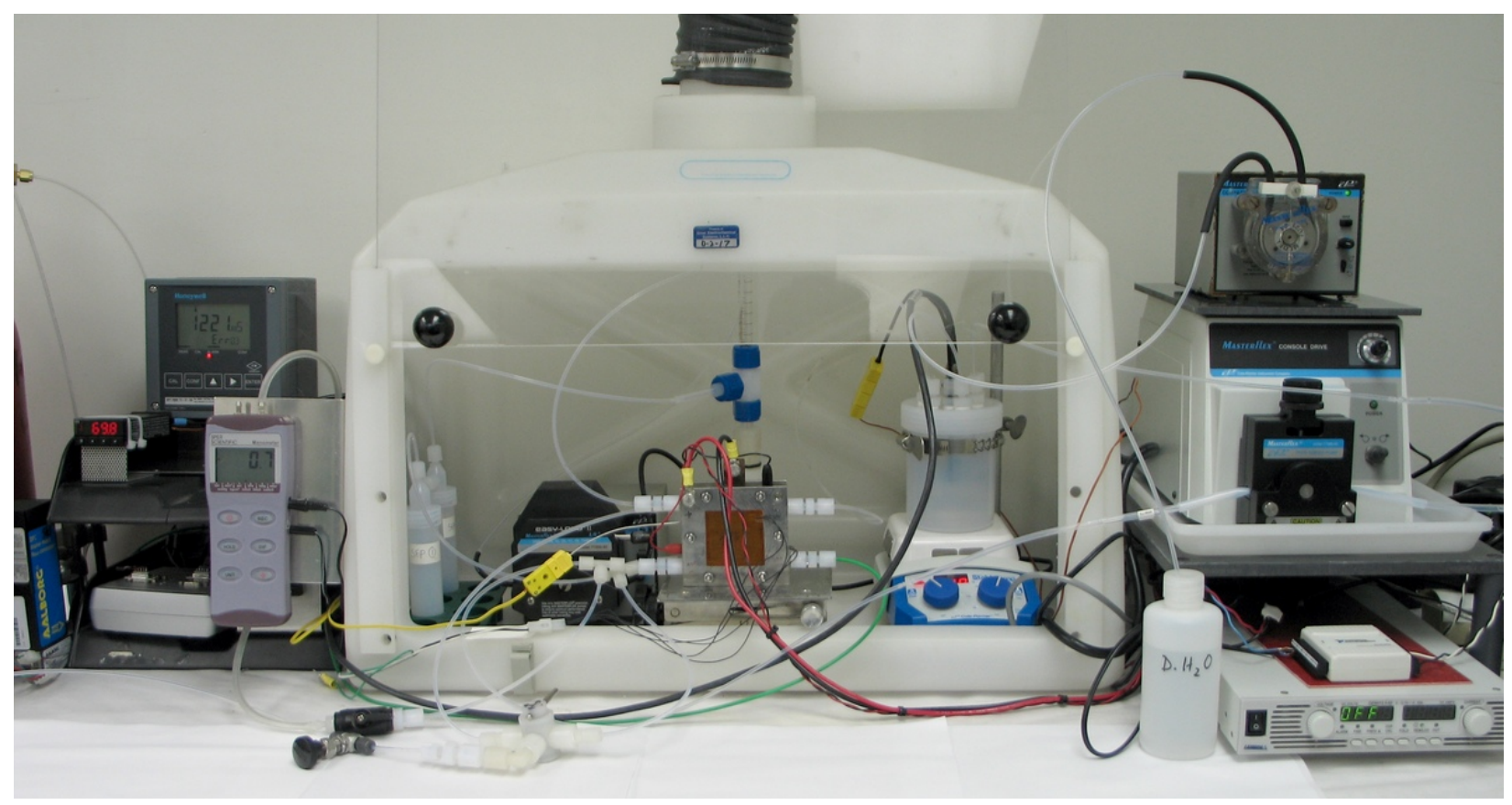

Figure 28. Photograph of SDE test stand modified for endurance testing.

Build NGA-13, comprised of a N1135 membrane with standard cathode and $4 \mathrm{mg} / \mathrm{cm}^{2}$ Pt black, 20\% Nafion catalyst on ETEK cloth anode was assembled and underwent the standard hydrogen pump testing, which exhibited somewhat higher resistance than the identically configured NGA- 07 build. Build NGA-13 was operated at $500 \mathrm{~mA} / \mathrm{cm}^{2}$ at $80^{\circ} \mathrm{C}$ under $\mathrm{SO}_{2}$ operation conditions (1.05x stoich nom.) for a total of 67 noncontinuous hours. As shown in (Figure 29), performance at $500 \mathrm{~mA} / \mathrm{cm}^{2}$ was highly dependent on the sulfuric acid concentration of the recirculating anolyte. Figure 32 more clearly shows the correlation between anolyte acid strength (which is going into the electrolyzer at this concentration: the produced acid strength is higher still). The polarization scans obtained during the endurance testing are shown in Figure 30; it is clear from this plot that there is no significant deterioration of the NGA electrolyzer performance over this period. It should be noted here that NGA-13 was rebuilt on two occasions due to seepage, but the cause of both seepage onsets was the blockage of the anode gap outlet ports. The tests dates and durations and nominal operating voltage for NGA-13 over the course of the endurance testing are shown in Figure 31. Again, there is no correlation with operation time and performance over the duration of the endurance testing up to 67 hours. 


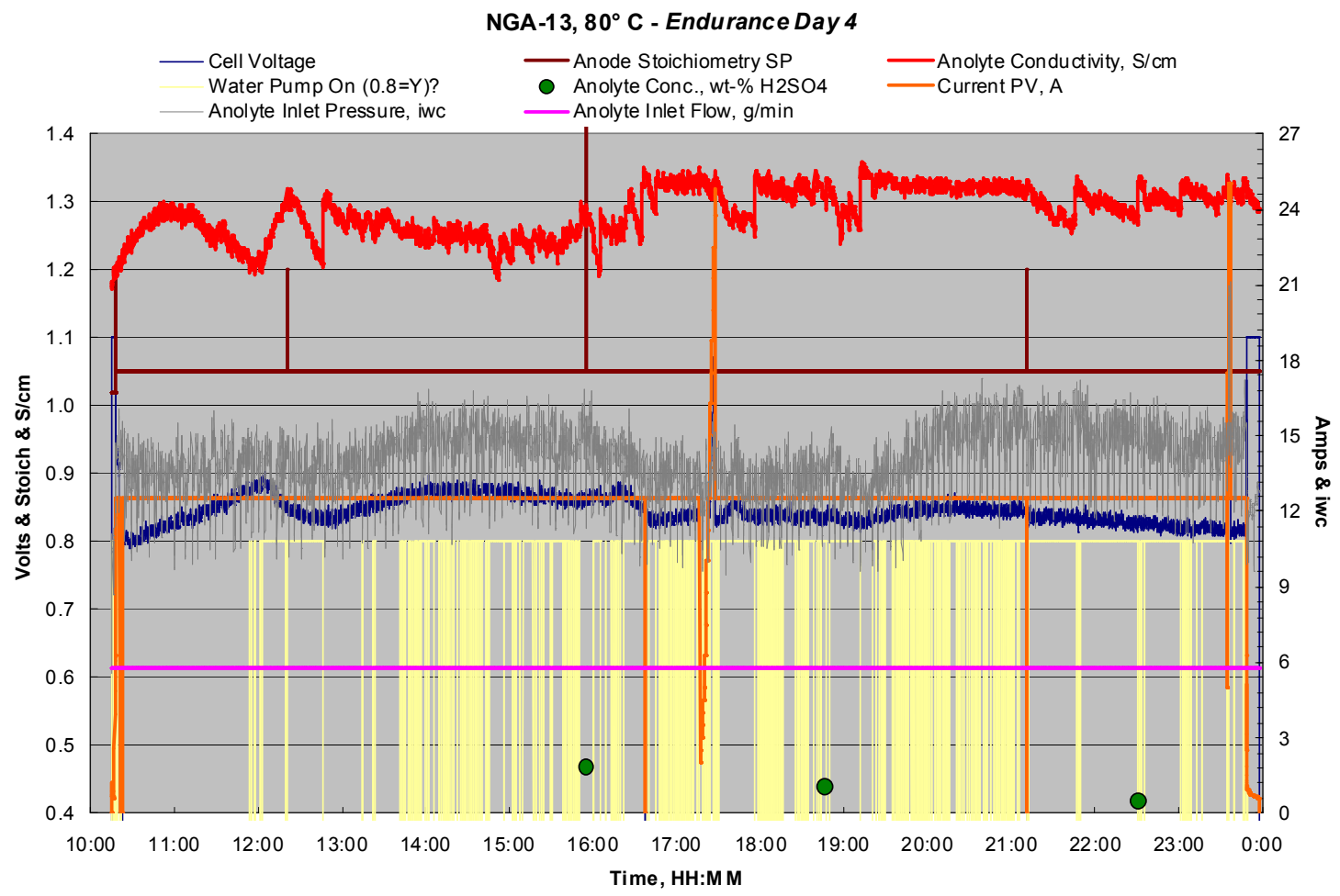

Figure 29. Timeplot of NGA-13 endurance testing over 13.7 hour run.

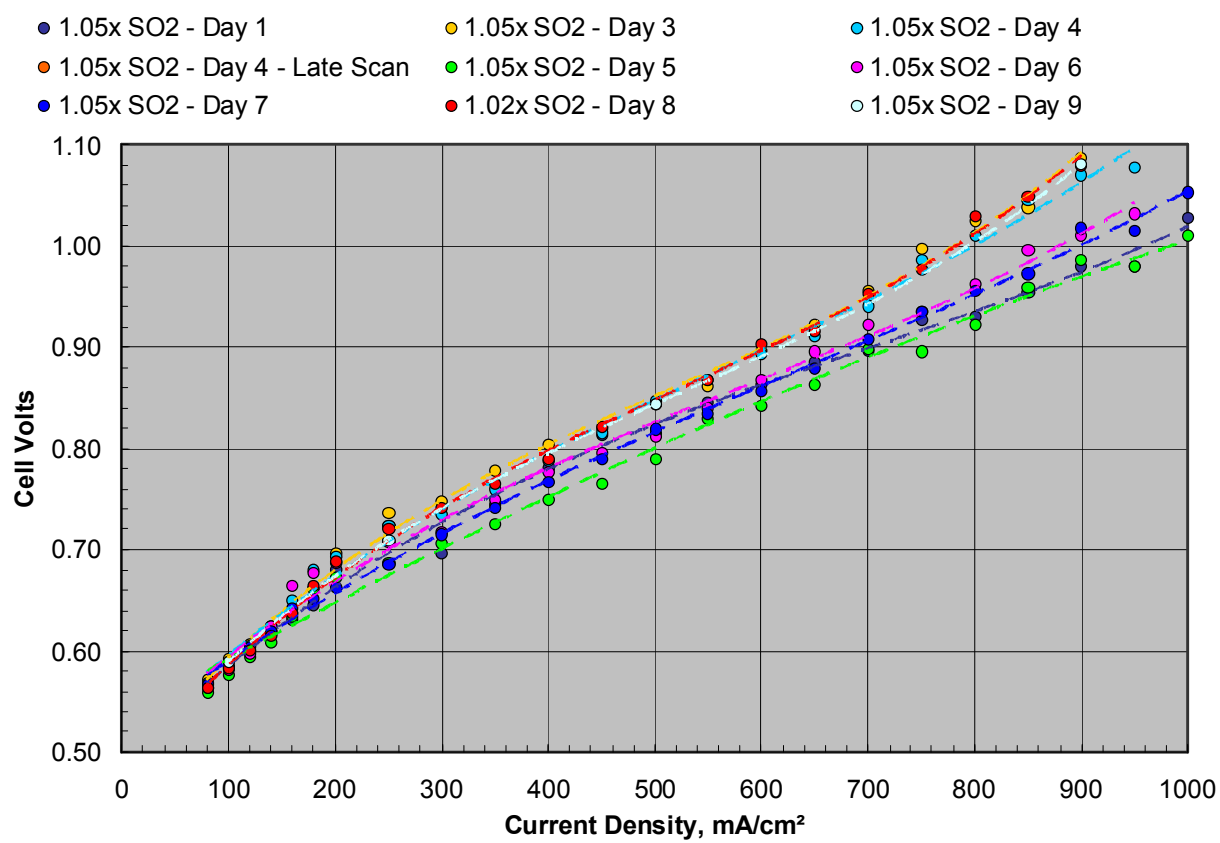

Figure 30. Graph of polarization scans during $80^{\circ} \mathrm{C}$ endurance testing of the NGA-13 build. 
NGA-13 Endurance Testing

\begin{tabular}{|c|c|c|c|}
\hline 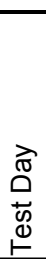 & $\begin{array}{l}\stackrel{0}{\oplus} \\
\stackrel{0}{0} \\
\stackrel{ \pm}{0} \\
\stackrel{5}{上}\end{array}$ & 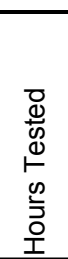 & 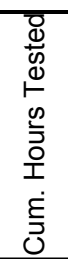 \\
\hline 1 & 11-Nov-09 & 5.8 & 5.8 \\
\hline 2 & 14-Nov-09 & 5.6 & 11.3 \\
\hline 3 & \begin{tabular}{|l|}
$18-N o v-09$ \\
\end{tabular} & 8.1 & 19.5 \\
\hline 4 & \begin{tabular}{|l|}
$19-N o v-09$ \\
\end{tabular} & 13.7 & 33.1 \\
\hline 5 & 20-Nov-09 & 7.2 & 40.3 \\
\hline 6 & $21-$ Nov-09 & 8.2 & 48.6 \\
\hline 7 & $25-N o v-08$ & 4.6 & 53.1 \\
\hline 8 & 5-Dec-09 & 3.0 & 56.1 \\
\hline 9 & 8-Dec-09 & 4.7 & 60.8 \\
\hline 10 & 9-Dec-09 & 6.6 & 67.4 \\
\hline
\end{tabular}

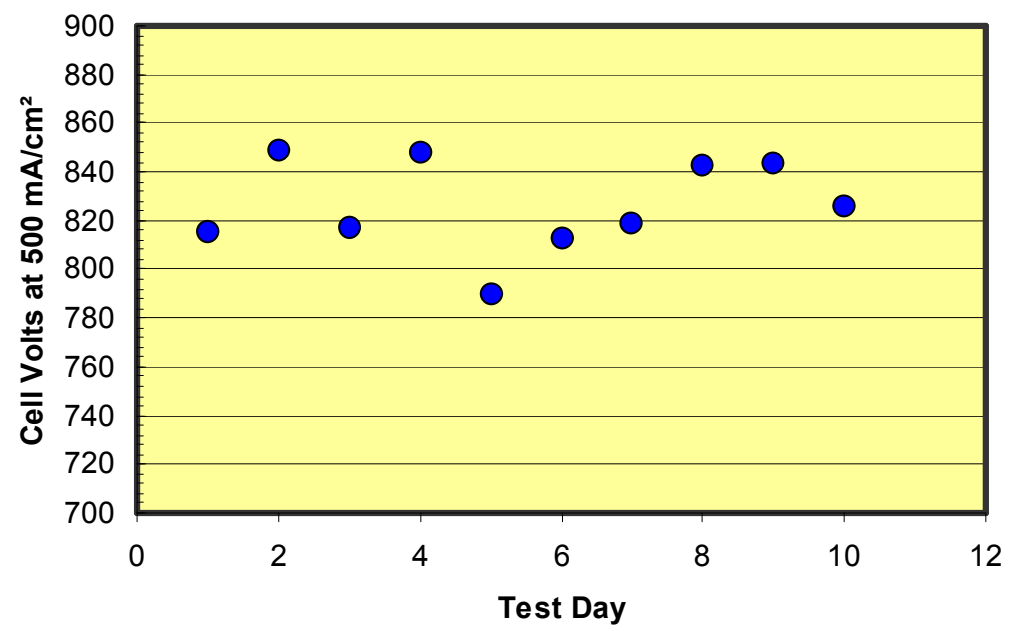

Figure 31. Chart of endurance test dates and durations (left) and graph of voltages observed for NGA-13 during endurance testing at $80^{\circ} \mathrm{C}$ and 1.02-1.05x $\mathrm{SO}_{2}$ stoichiometry (right). 


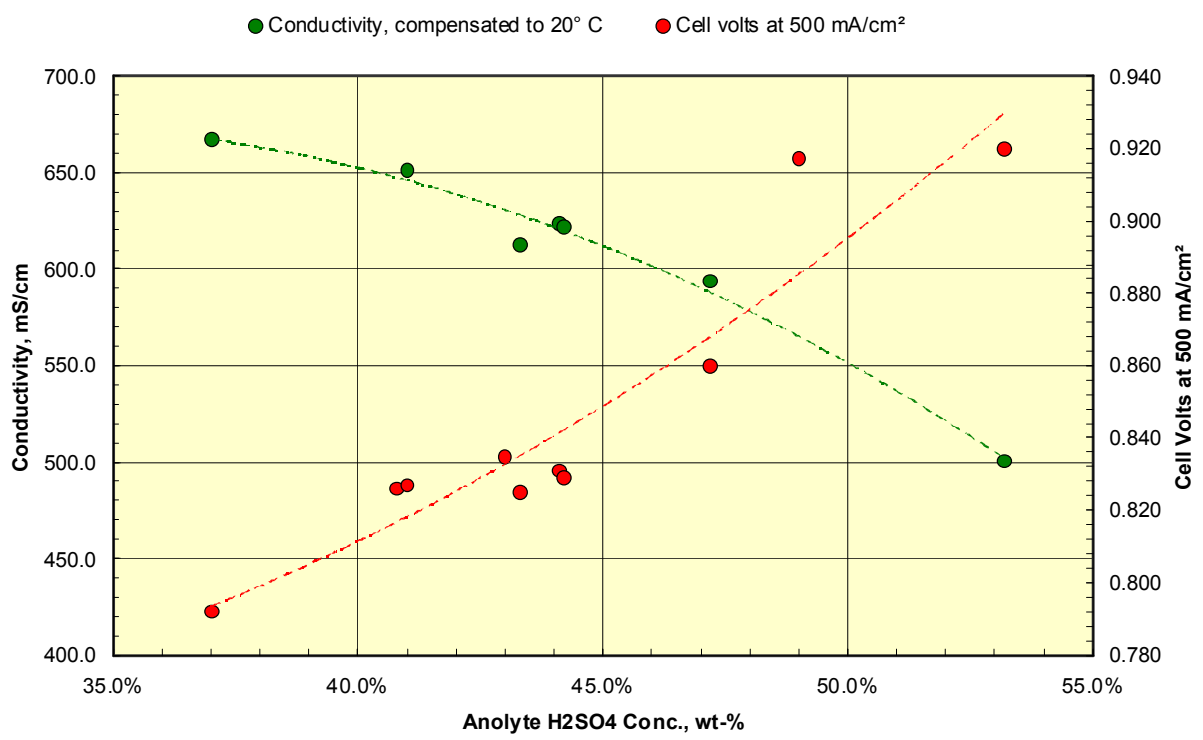

Figure 32. Graph of observed anolyte conductivity (temperature-compensated to $20^{\circ} \mathrm{C}$ ) and cell voltage vs. titrated anolyte acid strength for NGA-13 endurance testing.

\section{SULFUR CROSSOVER}

The tabular data included in Figure 6 has been plotted in Figure 33 and Figure 34 below to demonstrate that the $\mathrm{SO}_{2}$ crossover generally increases with decreased operating current density and increased anode $\mathrm{SO}_{2}$ stoichiometry, respectively. These observations are consistent with a basic model of crossover which states that the rate of diffusion of a solution-based species is dependent on its concentration near the electrolyte/PEM interface. Higher current density and higher $\mathrm{SO}_{2}$ utilization will both decrease $\mathrm{SO}_{2}$ concentration at this interface. It is generally observed from Figure 6 that $\mathrm{SO}_{2}$ crossover is not lower in the NGA-HyS cell vs. the USC-type cell.

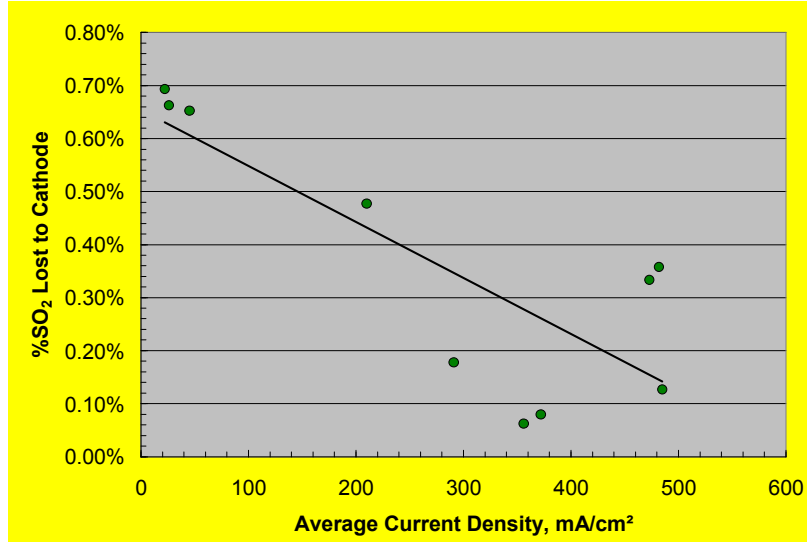

FIGURE 33. PLOT SHOWING TREND OF OBSERVED $\mathrm{SO}_{2}$ CROSSOVER VS. AVERAGE CURRENT DENSITY.

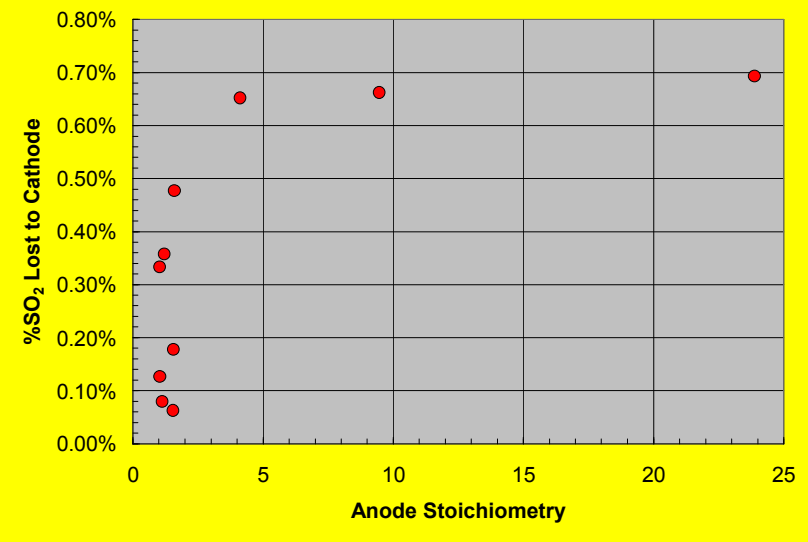

FIGURE 34. PLOT SHOWING TREND OF OBSERVED SO2 CROSSOVER VS. ANODE $\mathrm{SO}_{2}$ STOICHIOMETRY.

Sulfur formation experiment. Membrane discoloration (presumably sulfur) has been routinely observed in the anolyte port areas and around the periphery of the active area of the cathode of the HyS cells after operation. A pair of tests was designed to help elucidate the reaction conditions needed for this to occur. A piece of N1135 membrane was placed in a transparent polycarbonate test fixture designed to provide flow in strips on both sides of the sample, with reagent paths aligned for cross-membrane reaction testing. On one side of the test cell, water 
saturated with sulfur dioxide was pumped at $2 \mathrm{~g} / \mathrm{min}$. On the other, dry hydrogen gas was passed at $30 \mathrm{cc} / \mathrm{min}$ for the first test, and nitrogen gas with wet hydrogen sulfide was passed at $30 \mathrm{cc} / \mathrm{min}$ (using a fresh piece of membrane) for the second test. No visible change or reaction occurred with 3 hours of hydrogen testing. Yellow discoloration (presumably sulfur) was visible in 5 minutes on testing with hydrogen sulfide, and formed bulk deposits throughout the gas channels and gas exit port within one hour (Figure 35). The membrane was removed from the cell and washed; the gas channel path was marked on it by yellow stains that were not nondestructively removable (Figure 36). It is concluded that, for sulfur formation to occur in uncatalyzed regions of the Nafion membrane, the presence of both sulfur dioxide and hydrogen sulfide is required (Claus Reaction, Eq. 1), the hydrogen sulfide presumably produced in appreciable quantities at the HyS cathode from crossed-over sulfur dioxide by reduction at the hydrogen-evolving cathode catalyst.

$$
2 \mathrm{H}_{2} \mathrm{~S}+\mathrm{SO}_{2} \rightarrow 3 \mathrm{~S}+2 \mathrm{H}_{2} \mathrm{O}
$$

Further studies using this test configuration with platinum catalyst at the hydrogen/PEM interface will be helpful in further elucidating the requirements for sulfur layer formation in the HyS SDE environment. If sulfur layer formation is observed to be rapid when the first experiment $\left(\mathrm{H}_{2}\right.$ only, no $\left.\mathrm{H}_{2} \mathrm{~S}\right)$ is repeated with catalyst at the hydrogen/PEM interface, then it may suggest that the $\mathrm{H}_{2} \mathrm{~S}$ implicated in the sulfur formation reaction (Eq. 1) is formed by the catalyzed reaction between $\mathrm{H}_{2}$ and $\mathrm{SO}_{2}$ (Eq. 2).

$$
3 \mathrm{H}_{2}+\mathrm{SO}_{2} \rightarrow \mathrm{H}_{2} \mathrm{~S}+2 \mathrm{H}_{2} \mathrm{O}
$$

On the other hand, if the sulfur formation was not fast under these conditions, it would suggest that $\mathrm{H}_{2} \mathrm{~S}$ or an alternative sulfur progenitor (e.g., thiosulfate) may be formed preferentially by an electrochemical step (Eqs. 3 \& 4) exclusive of molecular hydrogen in the operating SDE. These studies are currently being undertaken at Giner Electrochemical Systems.

$$
\begin{aligned}
& \mathrm{SO}_{2}+6 \mathrm{e}^{-}+6 \mathrm{H}^{+} \rightarrow \mathrm{H}_{2} \mathrm{~S}+2 \mathrm{H}_{2} \mathrm{O} \\
& 2 \mathrm{SO}_{2}+4 \mathrm{e}^{-}+4 \mathrm{H}^{+} \rightarrow \mathrm{H}_{2} \mathrm{~S}_{2} \mathrm{O}_{3}+\mathrm{H}_{2} \mathrm{O}
\end{aligned}
$$


SRNL-OS-2009-00070, REVISION 0

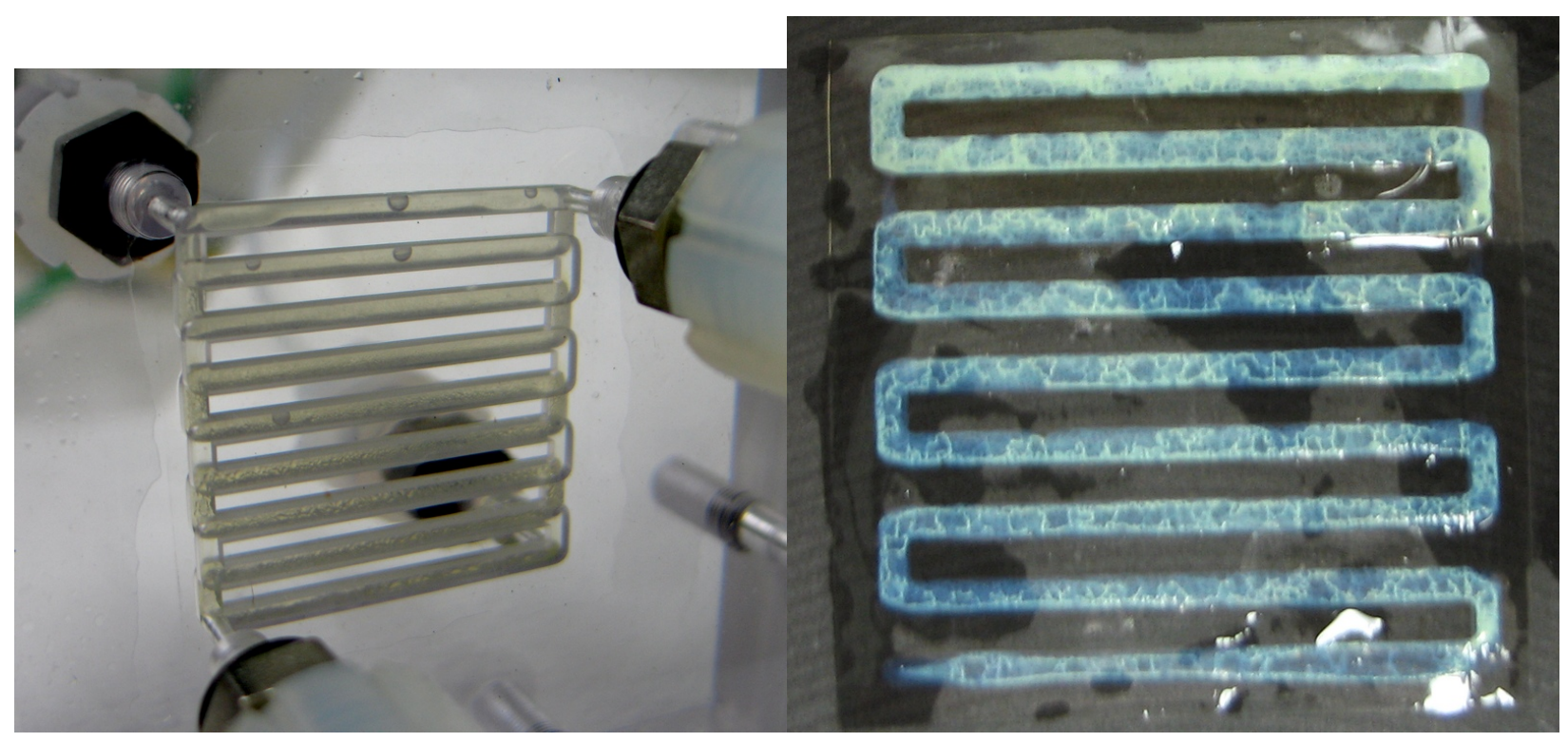

FIGURE 35. PHOTOGRAPH OF UNCATALYZED

FIGURE 36. PHOTOGRAPH OF UNCATALYZED MEMBRANE IN TEST HARDWARE DURING MEMBRANE OUT OF TEST HARDWARE SHOWING INITIAL STAGES OF SULFUR FORMATION.

DISTINCT AREAS OF SULFUR FORMATION.

\section{NGA-HYS DESIGN STUDY SYSTEM AND COST PROJECTIONS}

A rigorous design study of the NGA-HyS system and the associated cost projections were precluded by the technical challenges of the electrolyzer evaluation tasks, but a few salient points regarding this configuration can be put forth. 